\title{
A Presynaptic Role of Microtubule-Associated Protein 1/Futsch in Drosophila: Regulation of Active Zone Number and Neurotransmitter Release
}

\author{
Simon Lepicard, Bénédicte Franco, Frédéric de Bock, and Marie-Laure Parmentier \\ Institut de Génomique Fonctionnelle, CNRS-UMR5203, INSERM-U661, Université Montpellier, Montpellier, Cedex 5, F-34094, France
}

\begin{abstract}
Structural microtubule-associated proteins (MAPs), like MAP1, not only control the stability of microtubules, but also interact with postsynaptic proteins in the nervous system. Their presynaptic role has barely been studied. To tackle this question, we used the Drosophila model in which there is only one MAP1 homolog: Futsch, which is expressed at the larval neuromuscular junction, presynaptically only. We show that Futsch regulates neurotransmitter release and active zone density. Importantly, we provide evidence that this role of Futsch is not just the consequence of its microtubule-stabilizing function. Using high-resolution microscopy, we show that Futsch and microtubules are almost systematically present in close proximity to active zones, with Futsch being localized in-between microtubules and active zones. Using proximity ligation assays, we further demonstrate the proximity of Futsch, but not microtubules, to active zone components. Altogether our data are in favor of a model by which Futsch locally stabilizes active zones, by reinforcing their link with the underlying microtubule cytoskeleton.
\end{abstract}

Key words: active zone; microtubule-associated protein; microtubules; neuromuscular junction; synaptic release

\section{Introduction}

Structural microtubule-associated proteins (MAPs) are known to control the microtubule (MT) cytoskeleton organization, stabilization, and function (Nogales, 2001). The MAP1 family contains three members: MAP1A, MAP1B, and MAP1S. These proteins are cleaved in a heavy and a light chain, both chains being able to bind MTs. The three MAP1 genes show different patterns of expression: MAP1S is expressed ubiquitously (OrbánNémeth et al., 2005), and MAP1B is highly expressed during neuronal development with its expression diminishing during maturation. It is found in neurites and is especially enriched in growing axons (Halpain and Dehmelt, 2006). MAP1A is predominantly expressed in adult neurons and preferentially localizes in dendrites. All MAP1 proteins play a role in MT stabilization, and

Received Oct. 4, 2013; revised April 1, 2014; accepted April 2, 2014.

Author contributions:S.L., B.F., and M.-L.P. designed research;S.L., B.F., and F.d.B. performed research;S.L., B.F., F.d.B., and M.-L.P. analyzed data; S.L. and M.-L.P. wrote the paper.

This work was supported by an MRT fellowship to S.L. and a Chercheur d'Avenir grant from Région LanguedocRoussillon to M.-L.P. We thank the Vienna Drosophila Stock Center as well as the Bloomington Stock Center for providing fly stocks, and K. Klämbt, A. Diantonio, and S.J. Sigrist for sending antibodies and stocks; R. Kittel and M. Gho for their advice for NMJ electrophysiology; F. Bertaso, J. Cau, L. Fagni, S. Layalle, J. Mateos-Langerak, L. Soustelle, and Y. Grau for critical reading of the paper; M. Asari for help with 3D images and movies. The NC82 and 22C10 antibodies were obtained from the Developmental Studies Hybridoma Bank developed under the auspices of the NICHD and maintained by The University of lowa, Department of Biology; all confocal imaging and 3D-SIM imaging (with J. Mateos Langerak) was performed at the MRI IGH facility; and electron microscopy imaging was performed at the CRIC Facility (with C. Cazevieille) in Montpellier.

The authors declare no competing financial interests.

Correspondence should be addressed to Dr Marie-Laure Parmentier, IGF, 141 Rue de la Cardonille 34094 Montpellier, Cedex 05, F-34094 France. E-mail: Marie-Laure.Parmentier@igf.cnrs.fr.

B. Franco's present address: GIGA Lab, University of Liège, C.H.U. Sart Tilman, B-4000 Liège, Belgium.

DOI:10.1523/JNEUROSCI.4282-13.2014

Copyright $\odot 2014$ the authors $\quad 0270-6474 / 14 / 346759-13 \$ 15.00 / 0$ their transfection in heterologous cell systems induces the formation of MT bundles (Noiges et al., 2002). MAP1B knock-out mice revealed the developmental functions of the MAP1 family: MAP1B is involved in axonal branching and guidance, neurite growth or growth cone function (González et al., 2000; Meixner et al., 2000; Takei et al., 2000; González-Billault et al., 2001, 2002; Bouquet et al., 2004; Montenegro-Venegas et al., 2010).

More and more studies about MAP1 proteins highlight new roles different from MT stabilization and bundling. Indeed, MAP1S can bridge autophagic components with MTs (Xie et al., 2011), whereas MAP1A and MAP1B can interact directly or indirectly with receptors and channels: $\mathrm{GABA}_{\mathrm{C}}$ receptor (Hanley et al., 1999; Billups et al., 2000; Pattnaik et al., 2000), $\mathrm{Ca}_{\mathrm{V}} 2.2$ channels (Leenders et al., 2008), NMDA receptor subunit NR3A (Eriksson et al., 2010), or $\mathrm{Na}_{\mathrm{V}} 1.6$ sodium channel (O'Brien et al., 2012). These interactions with channels or receptors suggest a potential role of MAP1 proteins in neuronal communication by linking these proteins to MTs. A number of studies have focused on MAP1 proteins at the postsynapse (Trotta et al., 2004; Pangratz-Fuehrer et al., 2005; Zervas et al., 2005; Tortosa et al., 2011). However, presynaptic roles of MAP1 proteins are poorly studied: do MAP1 proteins play a role in neurotransmitter release and do they interact with components of the synaptic release machinery? We addressed these questions using the Drosophila model.

In Drosophila, there is only one representative of the whole MAP1 family: the gene futsch (Hummel et al., 2000). Futsch protein is cleaved similarly to MAP1 proteins in vertebrates (Zou et al., 2008). Like MAP1B in vertebrates, Futsch is involved in neurite growth in vivo, axonal guidance and neuronal development. It is specifically expressed in the nervous system, and colocalizes 
with the microtubule cytoskeleton at the well studied Drosophila larval neuromuscular junction (NMJ; Hummel et al., 2000; Roos et al., 2000; Ruiz-Canada et al., 2004). Hence, this cellular model is particularly suited to study the presynaptic function of the MAP1 protein Futsch. In the adult, loss of futsch leads to learning and memory behavioral defects that are followed by early neurodegeneration (Bettencourt da Cruz et al., 2005). These behavioral defects suggested the presence of synaptic dysfunction. Here, we studied the physiological function of presynaptic Futsch at the NMJ.

\section{Materials and Methods}

Fly stocks. The following fly lines were obtained from the Bloomington Stock Center: $y^{1} w^{1}$ (FBst0001495), our control stock, noted $+1+$ in the paper; $y^{1}$ futsch $^{\text {K68 }}$ (FBst0008794; Hummel et al., 2000); Df(1)Exel6227, $P\{X P-U\}$ Exel6227 $w^{1118} / F M 7 c$ (FBst0007704; Parks et al., 2004); $y^{1} s c^{*} v^{1}$; P\{TRiP.HMS01519\}attP2 (FBst0035770) containing a RNAi construct targeting the $k h c$ gene (Ni et al., 2009). The deficiency used transheterozygously with the $b r p^{69}$ mutation is $D f(2 R) B S C 29, c n^{1} b w^{1} s p^{1} / C y O$ (FBst0006917; Parks et al., 2004). The $b r r^{69}$ mutant allele (Kittel et al., 2006) was a kind gift from S. Sigrist (Freie Universitaet Berlin, Germany). We also used stocks encoding either Brp-GFP (Fouquet et al., 2009) or Cacophony-GFP (Kawasaki et al., 2004): $w^{*}$; P\{UAS-brp.GFP $\}$ TR725 (FBst0036292) and $w^{*} ;$ P $\{U A S-c a c 1-E G F P\} 422 A$ (FBst0008582).

The stock containing a RNAi construct targeting the $\alpha$ Tub84B gene was obtained from the Vienna Drosophila RNAi Center (Dietzl et al., 2007): $w^{1118}$; $P\{G D 9679\} v 33427$ (FBst0460094). The OK6-Gal4 line (Sanyal, 2009) was a kind gift from C. O'Kane (University of Cambridge, UK). For all experiments, we used females.

Two-electrode voltage-clamp recordings. Electrophysiological recordings at the NMJ were achieved using two-electrode voltage-clamp methods as described previously (Rohrbough et al., 1999). Wandering third-instar larvae were dissected in cold hemolymph-like HL3.1 saline solution without calcium (Feng et al., 2004). After dissection, larvae were placed in a recording chamber containing HL3.1 solution supplemented with $0.45 \mathrm{mM} \mathrm{CaCl}_{2}$ (or 0.2 or $1.8 \mathrm{mM} \mathrm{CaCl}_{2}$ ). All recordings were made at $16-18^{\circ} \mathrm{C}$ from muscle 6 of segment A3. Sharp borosilicate electrodes filled with $3 \mathrm{M} \mathrm{KCl}$ and with a resistance of $8-25 \mathrm{M} \Omega$ and were used for intracellular recordings. Evoked excitatory junctional currents (eEJCs) were stimulated with a glass suction electrode on the appropriate segmental nerve at a suprathreshold voltage level. All current recordings were performed in voltage-clamped muscle $\left(\mathrm{V}_{\text {hold }}=-60 \mathrm{mV}\right)$ using an Axoclamp 200B amplifier (Molecular Devices). Signals were sampled at $(10 \mathrm{kHz})$ using pClampex software and analyzed with Clampfit 10.2 software (Molecular Devices). For estimation of readily releasable pool (RRP) size, we applied the same protocol as in (Graf et al., 2012).

Immunocytochemistry. Wandering third instar larvae were dissected in

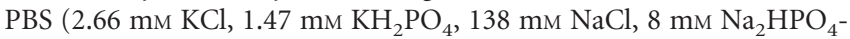
$7 \mathrm{H}_{2} \mathrm{O}, \mathrm{pH}$ 7.4), EDTA $1 \mathrm{~mm}$, and then fixed for $20 \mathrm{~min}$ in $4 \%$ paraformaldehyde in PBS or in Bouin's fixative for DGluRIII/DGluRIIC stainings. Immunostainings were performed in PBS $1 \times, 0.3 \%$ Triton X-100, 0.25\% BSA. The following antibodies were used: polyclonal rabbit or goat anti-HRP (Sigma-Aldrich, 1:1000), polyclonal sheep anti-tubulin (pan-specific, ATN02, Millipore Bioscience Research Reagents, 1:300), polyclonal rabbit anti-Futsch ${ }^{\mathrm{N} \text {-term }}$ or anti-Futsch ${ }^{\mathrm{C}-\text { term }}$ as described by Gögel et al. ( 2006), polyclonal anti-DGluRIII (DGluRIIC) as described by Marrus et al. (2004), polyclonal rabbit anti- $\alpha$ Tubulin (ab15246, Abcam, 1:200), polyclonal rabbit anti-Bruchpilot ${ }^{\mathrm{N} \text {-term }}$ (Fouquet et al., 2009), mouse monoclonal anti- $\alpha$ Tubulin (DM1A, Sigma-Aldrich, 1:200), mouse monoclonal anti-betatubulin (E7, Developmental Studies Hybridoma Bank; DSHB, 1:200), mouse monoclonal anti-Futsch (22C10, DSHB, 1:200), mouse monoclonal NC82 (DSHB, 1:60). Fluorescent secondary antibodies were from Jackson ImmunoResearch (donkey anti-rabbit Cy3, donkey anti-mouse Cy3, donkey anti-goat Cy5), Invitrogen (donkey anti-rabbit AlexaFluor 488 and donkey anti-mouse AlexaFluor 488) or Santa Cruz Biotechnology (donkey anti-rabbit IgGCFL 405; sc-362251). Goat anti-HRP antibodies conjugated with Cy3 or Cy5 (Jackson Immunoresearch) were used at 1:500. Preparations were mounted in Vectashield media (Clinisciences) for confocal imaging or in ProLong gold (Invitrogen) for 3D-SIM observations.

In situ PLA. We performed Duolink proximity ligation assay (PLA; O-Link Bioscience) on NMJ preparations. The first steps were similar to the immunocytochemistry protocol (up to overnight incubation with primary antibodies). Washes with the PLA kit buffer were then performed, secondary antibodies conjugated with oligonucleotides (PLA probes) were added, and all subsequent steps followed the kit instructions. A ligation step is performed in situ so that, when the secondary antibodies are close enough $(<40 \mathrm{~nm})$, a closed circle of DNA is generated. An amplification step is then performed with fluorescent oligonucleotides. This amplification occurs only in presence of closed circular DNA and produces a fluorescent spot.

In more details, fixed larvae were incubated with specific mouse and rabbit primary antibodies overnight at $4^{\circ} \mathrm{C}$ with Cy5-conjugated antiHRP antibody raised in Goat (Jackson ImmunoResearch) at 1:500. After washing (Buffer SSC: $3 \times 5$ min), PLA probes (anti-mouse PLUS and PLA probe anti-rabbit MINUS) diluted in the blocking agent (dilution 1:5) were incubated for $1 \mathrm{~h}$ at $37^{\circ} \mathrm{C}$. Unbound PLA probes were removed by washing (Buffer A: $2 \times 5 \mathrm{~min}$ ). Larvae were then incubated in the ligation solution consisting of Duolink Ligation stock (1:5) and Duolink Ligase (1:40) for $30 \mathrm{~min}$ at $37^{\circ} \mathrm{C}$. After washing (Buffer A: $2 \times 2 \mathrm{~min}$ ), the amplification step using the amplification stock (1:5) and the polymerase (1:80) was done for $1 \mathrm{~h}$ at $37^{\circ} \mathrm{C}$. Final washing steps were done in $1 \times$ wash buffer for $2 \times 10 \mathrm{~min}$ and $0.01 \times$ wash Buffer B for $1 \mathrm{~min}$. We performed PLA experiments with a $\mathrm{Cy} 3$ dye so that interactions between the two targeted proteins were visible in "red". After washes, the preparation was mounted in Vectashield media (Clinisciences). In parallel to the PLA protocol, we added Cy5-conjugated anti-HRP antibody raised in goat (Jackson ImmunoResearch) 1:500 to the primary antibodies to be able to visualize the synaptic terminal. This had no effect on the PLA results.

Imaging and analysis. Confocal images were acquired using a Zeiss LSM 510 Meta and a Zeiss LSM780 confocal microscopes (Montpellier RIO Imaging, Institute of Human Genetics) equipped with 488, 561, and $633 \mathrm{~nm}$ lasers, the corresponding dichroic and filter sets and an Zeiss $63 \times / 1.4$ PL-APO DIC oil-immersion objective. Images were acquired with ZEN software.

Morphology of NMJs was analyzed using ImageJ/Fiji software. All analyses were done maximal intensity projections. After thresholding, the total HRP area was measured using the "analyze particle" function by setting the minimum size of particle so that only the contour of the NMJ was selected. To measure the bouton size, individual boutons were delineated by hand and their area measured. To quantify the number of Brp-positive active zones, images were thresholded to suppress the background and the number of particles measured with the analyze particle function. Student's $t$ tests were performed for statistical analysis.

To highlight zones of colocalization between Futsch and MTs in multiple labeling 3D-SIM images, the colocalization plugin was used with the following settings: ratio $=40 \%$; threshold for each channel $=50$.

Transmission electron microscopy. Third instar larvae were dissected in PBS $1 \times$, EDTA $1 \mathrm{~mm}$. Larval preparations were then fixed overnight in $5 \%$ glutaraldehyde in $0.1 \mathrm{M}$ phosphate buffer $\left(\mathrm{NaH}_{2} \mathrm{PO}_{4}, 2 \mathrm{H}_{2} \mathrm{O}\right.$ and $\left.\mathrm{Na}_{2} \mathrm{HPO}_{4}, 2 \mathrm{H}_{2} \mathrm{O}\right)$. They were then rinsed in phosphate buffer and postfixed in a $1 \%$ osmic plus $0.8 \%$ potassium ferrocianide for $2 \mathrm{~h}$ at dark and room temperature. After two rinses in a phosphate buffer, larval preparations were dehydrated in a graded series of ethanol solutions (30100\%). Larval preparations were embedded in EMBed 812 DER 736. Thin sections ( $85 \mathrm{~nm}$; Leica-Reichert Ultracut E) were collected at different levels of each block. These sections were counterstained with uranyl acetate and lead citrate and observed using a Hitachi 7100 transmission electron microscope in the Centre de Ressources en Imagerie Cellulaire de Montpellier.

$3 D$-SIM. Dissected larvae were mounted on high precision \#1.5H coverslips (Marienfeld $\mathrm{GmbH}$ ). 3D structured illumination microscopy (3D-SIM) imaging was performed on an OMX V3 microscope (Applied Precision). To accurately locate the NMJ innervating muscles 6 and 7, we used a Personal Deltavision (Applied Precision) equipped with lowmagnification optics and mapped the coordinates to the OMX. Reconstruction and image registration of the 3D-SIM images was performed 
using softWoRx v5.9 (Applied Precision). Blue, green, and red fluorescent PS-speck beads ( $170 \mathrm{~nm}$; Life Technologies) were used to measure the optical transfer function used for the 405,488 , and 561 channels. TetraSpeck beads (200 nm; Invitrogen) were used to verify the image registration quality.

\section{Results}

Futsch is required for normal glutamate release

At the NMJ, the MAP1 homolog Futsch is only present at the presynaptic side; i.e., in the motor neuron synaptic terminal. To test whether presynaptic Futsch was important for synaptic physiology, we undertook two-electrode voltage-clamp recordings of third instar larvae NMJs (muscle 6). We compared control and futsch mutants. We used the futsch ${ }^{K 68}$ allele either homozygous, or transheterozygous with a deficiency covering futsch gene. We chose this allele because it was previously shown to display a morphological phenotype at the larval NMJ (Roos et al., 2000; Gögel et al., 2006). We first quantified spontaneous vesicular release by measuring miniature excitatory junction currents (mEJCs) in $0.45 \mathrm{mM} \mathrm{Ca}^{2+}$ (Fig. 1A). There was no significant difference in the frequency and amplitude of mEJCs between futsch mutants and controls (Fig. $1 B, C$ ). This indicates that spontaneous vesicular release is normal in futsch mutants, and that there is no gross difference in postsynaptic glutamate receptor fields between futsch mutants and controls. We then measured evoked excitatory junction currents (eEJCs) amplitudes upon 1 $\mathrm{Hz}$ nerve stimulation (Fig. 1D). We observed a significant decrease of futsch mutant eEJC amplitudes with respect to controls (Fig. 1E). Because mEJCs were unchanged, the defect in eEJC amplitude was probably the consequence of a reduction of the mean number of synaptic vesicles released upon nerve stimulation. Indeed, this number, which is estimated by the quantal content $(\mathrm{QC}=\mathrm{eEJC} / \mathrm{mEJC})$, is significantly reduced in futsch mutant condition compared with controls (Fig. $1 F$ ). Altogether, these results show that loss of Futsch is responsible for a presynaptic defect in neurotransmitter release.

Two parameters dictate the efficacy of neurotransmitter release: the number of available quanta of neurotransmitter $(n)$, and the probability of their release $(p)$. Modifications of one (or both) of these parameters could account for the defects observed in futsch mutants. For instance, the probability $p$ could be affected by modification of calcium entry or sensitivity in the presynapse of futsch mutants. We tested this hypothesis by performing paired-pulse facilitation in control and futsch mutants. Pairedpulse facilitation is an enhancement of neurotransmitter release caused by elevation of residual $\mathrm{Ca}^{2+}$ in the nerve terminal (Zucker and Regehr, 2002). We applied two stimuli spaced 25, 50, and $100 \mathrm{~ms}$ apart and recorded eEJCs in $0.45 \mathrm{mM} \mathrm{Ca}^{2+}$. The extent of facilitation was expressed as the paired-pulse ratio: eEJC2/eEJC1. No change was detected in futsch mutants (Fig. $1 G, H)$. This indicated that there is no change in calcium dynamics in these mutants. We also quantified eEJC rise time. This parameter is controlled by the calcium availability and is modified in mutants of the active zone component Bruchpilot, in which the number of calcium cacophony channels is decreased (Kittel et al., 2006). Here, we could not find any significant change in eEJC rise time in futsch mutants (Fig. 1I). We tested the calcium-dependency of vesicular release in control and futsch mutants. In the linear range of the dose-response curve (between 0.2 and $0.45 \mathrm{~mm}$; Dodge and Rahamimoff, 1967), there was no change in the slope (Fig. $1 \mathrm{~J}, \mathrm{~K})$. Altogether these results confirmed that $\mathrm{Ca}^{2+}$ dynamics remain unchanged in futsch mutants. Remarkably, the difference in quantal content between control
A



D



E
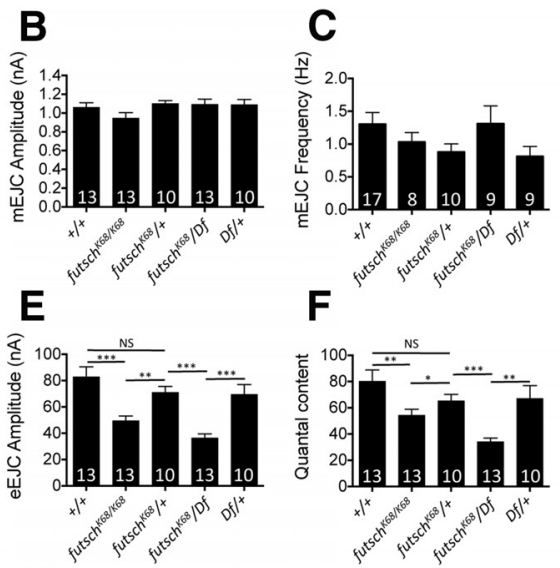

$\mathbf{G}_{+/+\quad f u t s c h}^{K 68 / / 68}$

H Paired-Pulse Facilitation I
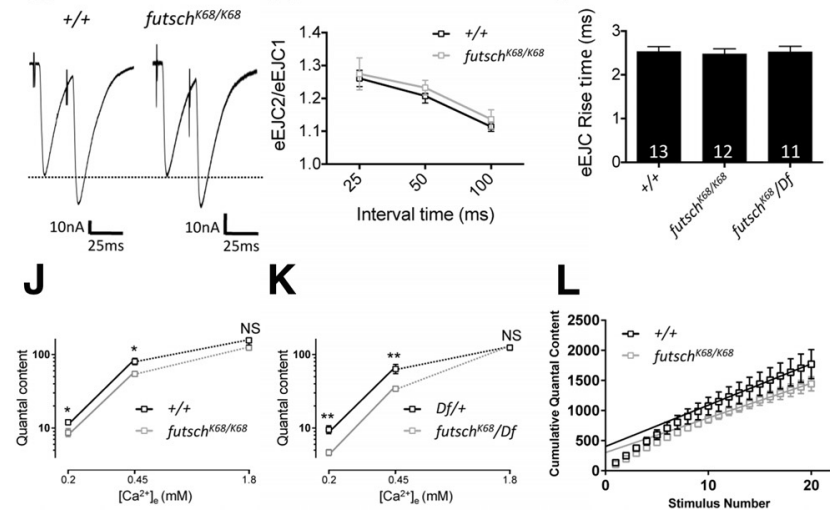

K

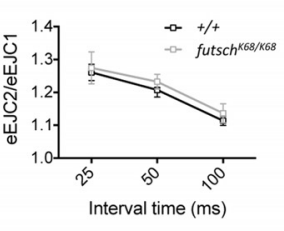

$\mathbf{L}$
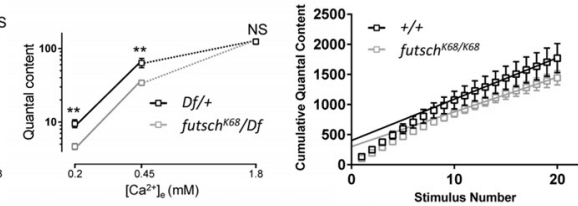

Figure 1. futsch is required for normal glutamate release at larval NMJ. Electrophysiological recordings at muscle $6 / 7$ in segment $A 3$ of wandering third instar larvae. Extracellular calcium concentration is $0.45 \mathrm{~mm}$. Histograms indicate mean $\pm S E M$ values with the number of tested larvae for each genotype indicated. $\boldsymbol{A}$, Representative mEJCs traces for $+/+$ and futsch ${ }^{K 68 / K 68}$ larvae. $\boldsymbol{B}, \boldsymbol{C}$, Mean amplitude $(\boldsymbol{B})$ and frequency $(\boldsymbol{C})$ of $\mathrm{mEJ}(\mathrm{s}$ : there is no significant difference between controls and futsch mutants. $\boldsymbol{D}$, Representative eEJCs traces from $+1+$ and futsch ${ }^{K 68 / K 68}$ larvae. $\boldsymbol{E}, \boldsymbol{F}$, Mean eEJC amplitude $(\boldsymbol{E})$ and mean $Q C$ $(\mathrm{eEJ} / \mathrm{mEJC} ; \boldsymbol{F})$ : there is a significant decrease of eEJC amplitude and QC in futsch mutants compared with controls. QC is an estimation of the total number of synaptic vesicles released upon an action potential. $\mathbf{G}$, Representative paired-pulse traces for $+1+$ and futsch ${ }^{K 68 / K 68}$ larvae. $\boldsymbol{H}$, Mean PPF ratio (eEJC2/eEJC1) in control and futsch ${ }^{K 68 / K 68}$ mutant measured for 25, 50, and 100 ms time intervals. No change in PPF ratio was observed in futsch mutant compared with control. I, Mean eEJC rise time (time between 10 and $90 \%$ of the maximum amplitude) in control and futsch mutants. There is no significant difference between control and futsch mutants. J, QC of control and futsch ${ }^{K 68 / K 68}$ larvae at different calcium concentrations ( $n=8$ for control and futsch ${ }^{K 68 / K 68}$ mutants at $0.2 \mathrm{mMCa}^{2+}, n=8$ for control and $n=12$ for futsch ${ }^{K 68 / K 68}$ at $\left.1.8 \mathrm{~mm} \mathrm{Ca}^{2+}\right)$. Mean QCs are significantly different between control and futsch ${ }^{K 68 / K 68} \mathrm{mu}$ tants at 0.2 and $0.45 \mathrm{~mm} \mathrm{Ca}^{2+}$. The slope of the linear part of the curve (plain lines) appears unchanged in futsch ${ }^{K 68 / K 68}$ mutants. $K, \mathrm{QC}$ of Df/ + and futsch ${ }^{K 68} / \mathrm{Df}$ larvae at different calcium concentrations ( $n=8$ for $D f /+$ and $n=5$ for futsch ${ }^{K 68} / D$ f mutants at $0.2 \mathrm{~mm} \mathrm{Ca}^{2+}, n=9$ for $D f /+$ and futsch ${ }^{K 68} / D f$ larvae at $1.8 \mathrm{~mm} \mathrm{Ca}^{2+}$ ). The slope of the linear part of the curve (plain lines) appears unchanged in futsch ${ }^{K 68} / D$ f larvae compared with Df/ + larvae. $L$, Cumulative QC plots for control $(n=7)$ and the futsch ${ }^{K 68 / K 68}$ mutant $(n=8)$ backextrapolated to time 0 to estimate RRP size. NS, Not significant; ${ }^{*} p<0.05,{ }^{* *} p<0.01$, ${ }^{* * *} p<0.001$.

and futsch mutants decreased at high $\mathrm{Ca}^{2+}$ concentration (1.8 $\mathrm{mM}$ ), indicating that an excess of $\mathrm{Ca}^{2+}$ can compensate futsch synaptic defects (Fig. $1 \mathrm{~J}, K$ ). We then tested whether the decrease in synaptic vesicular release in futsch mutants could be due to a decrease in the overall number of available quanta, $(n)$. The size of the RRP of vesicles can be estimated using an electrophysiological approach with high-frequency stimulation and high $\mathrm{Ca}^{2+}$ concentration (Schneggenburger et al., 2002; Graf et al., 2012). We obtained an estimate of $416 \pm 81$ vesicles in control larvae $(n=7)$, compared with $302 \pm 35$ in futsch ${ }^{K 68}$ mutants $(n=8 ; p=$ 
Table 1. Quantification of the number and size of synaptic lb boutons

\begin{tabular}{|c|c|c|c|c|c|}
\hline & lb No. & Ib area $\left(\mu \mathrm{m}^{2}\right)$ & $\begin{array}{l}\text { Ib longer branch } \\
(\mu \mathrm{m})\end{array}$ & $\begin{array}{l}\text { Synaptic span } \\
\left(\mu \mathrm{m}^{2}\right)\end{array}$ & $\begin{array}{l}\text { Area lb }+ \text { Is/NMJ } \\
\left(\mu \mathrm{m}^{2}\right)\end{array}$ \\
\hline$+/+(n=12)$ & $40 \pm 3$ & $7.76 \pm 0.41$ & $85.5 \pm 6.6$ & $654 \pm 35$ & $438 \pm 21$ \\
\hline futsch $^{K 68 / K 68}(n=16)$ & $24 \pm 2^{* * *}$ & $9.44 \pm 0.53^{*}$ & $79.2 \pm 5.3^{\mathrm{ns}}$ & $497 \pm 39^{* *}$ & $353 \pm 22^{*}$ \\
\hline futsch ${ }^{K 68} /+(n=13)$ & $30 \pm 2^{n s}$ & $8.21 \pm 0.29^{\mathrm{ns}}$ & $95.8 \pm 5.9^{*}$ & $533 \pm 27^{p=0.08}$ & $377 \pm 17^{\mathrm{ns}}$ \\
\hline futsch $^{K 68} / D f(n=16)$ & $28 \pm 2$ & $8.57 \pm 0.45$ & $77.0 \pm 4.6$ & $464 \pm 25$ & $363 \pm 26$ \\
\hline$D f /+(n=12)$ & $31 \pm 3^{\mathrm{ns}}$ & $8.88 \pm 0.70^{\mathrm{ns}}$ & $102.9 \pm 6.8^{* *}$ & $576 \pm 32^{*}$ & $396 \pm 19^{\mathrm{ns}}$ \\
\hline $0 K 6 /+(n=20)$ & $45 \pm 4$ & $7.48 \pm 0.33$ & $89.2 \pm 6.9$ & $694 \pm 44$ & $494 \pm 35$ \\
\hline OK6>Tub84B RNAi $(n=17)$ & $32 \pm 2^{* *}$ & $8.18 \pm 0.25^{p=0.11}$ & $72.7 \pm 6.0^{p=0.08}$ & $569 \pm 30^{*}$ & $416 \pm 26^{p=0.08}$ \\
\hline
\end{tabular}

The total area occupied by lb and ls boutons was also measured as well as the total synaptic span (total area covered by the NMJ after maximal projection of confocal stacks). This was done on muscle $6 / 7$ NMJs in A3 segment of wandering third instar larvae.

HRP antibody was used to label junctions. Numbers are mean \pm SEM values. Student's $t$ test was performed between $+/+$ and futsch ${ }^{K 68 / K 68}$ in the top part of the table. Student's $t$ test was performed between futsch $h^{K 68} / D f$ and futsch $h^{K 68} /+$ (top row) and between futsch ${ }^{K 68} / \mathrm{Df}$ and $D \mathrm{f} /+$ (bottom row) in the middle part of the table. Student's test was performed between $0 K 6 /+$ and $0 K 6>R N A i T u b 84 B$ in the bottom part of the table. ns, Not significant; ${ }^{*} p<0.05$, ${ }^{* *} p<0.01$, ${ }^{* * *} p<0.001$.

0.2; Fig. $1 K)$, Although the difference was not statistically significant, one noticed a tendency for the size of the RRP to decrease in futsch mutants.

\section{futsch mutation affects NMJ synaptic span}

To further analyze this RRP decrease in futsch mutants, we measured the number of active zones using morphological and immunocytochemical techniques. Indeed, the number of active zones may be reduced in futsch mutants because of a reduction in the number of synaptic boutons. This hypothesis is supported by the reduced number of boutons previously reported in muscle 4 NMJs of the futsch ${ }^{K 68 / K 68}$ mutants (Roos et al., 2000; Gögel et al., 2006). We tested whether the reduction in bouton number was also present at muscle 6/7 NMJs, by analyzing the morphology of muscle 6/7 NMJ of control, futsch ${ }^{\mathrm{K} 68 / \mathrm{K} 68}$, and futsch ${ }^{\mathrm{K} 68} / \mathrm{Df} \mathrm{mu}-$ tants. We labeled NMJs using anti-HRP antibodies, known to specifically bind to membrane epitopes within the insect nervous system. We counted the number of the two types of synaptic boutons that are visible at muscle 6/7 NMJs: type I big (Ib) and small (Is) boutons. We also measured the size of the Ib bouton, the total area of boutons (Ib and Is) and the total synaptic span of the NMJ.

When comparing control and futsch ${ }^{\mathrm{K} 68 / \mathrm{K} 68}$ larvae, we observed a decrease in Ib bouton number and an increase in bouton size (Table 1). We also observed a significant decrease of the total HRP area (synaptic span) in these mutants (Table 1). However, when comparing futsch ${ }^{K 68} / \mathrm{Df}$ mutants with their respective heterozygote controls ( futsch $\mathrm{K}^{\mathrm{K} 8} /+$ and $+/ D f$ ), we could not detect a significant difference in Ib bouton number or Ib bouton size between these genotypes. Nevertheless, we could still observe a significant decrease of the synaptic span. We confirmed that this was not the consequence of a change in the total bouton area, by measuring total $\mathrm{Ib}$ and Is bouton area (Table 1 ): there was no significant change between futsch ${ }^{K 68} / D f$ mutants and the heterozygote controls. Hence, the change in synaptic span may be the consequence of a change in bouton and/or branch organization (bouton spacing, branch length, number of branches). We looked at maximal branch length and could see a significant decrease of the mean length of the Ib longer branch in futsch/Df mutant compared with controls (Table 1). In conclusion, loss of Futsch leads to a reduction of NMJ synaptic span, without consistently affecting bouton size and number at muscle 6/7 NMJs.

\section{Active zone number and density are modified in} futsch mutants

Because we could not find any clear decrease in bouton number in futsch mutants, we directly quantified whether there was a
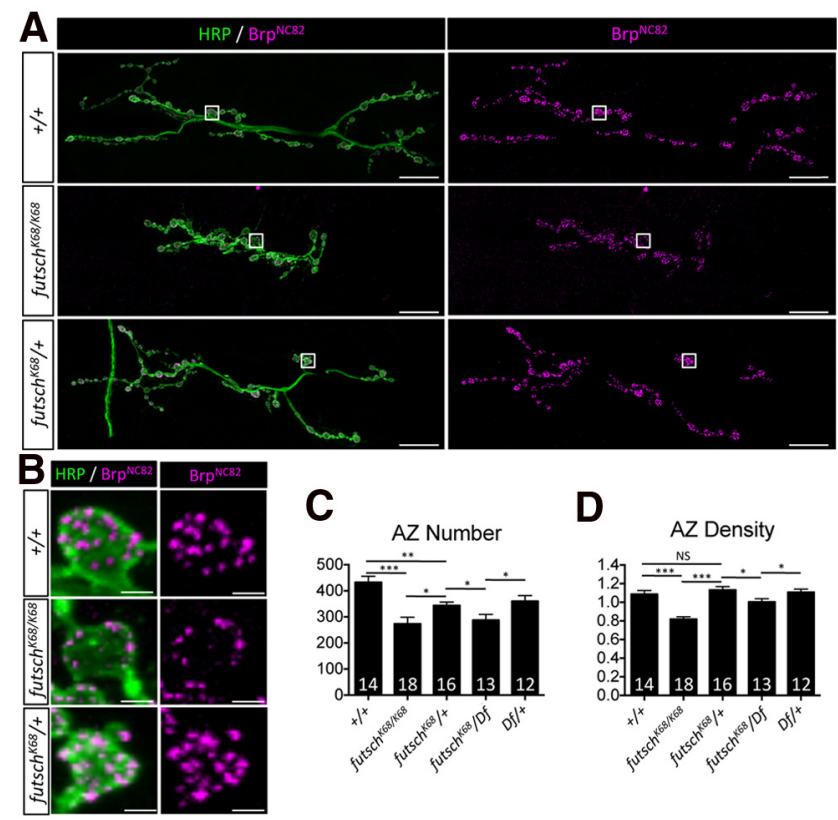

Figure 2. AZ number and density are modified in futsch mutants. Quantification of AZ number and density at muscle 6/7 NMJs (segment A3) of wandering third instar larvae. A, Representative NMJs of $+/+$, futsch ${ }^{K 68 / K 68}$ and futsch ${ }^{\mathrm{K} 68} /+$ larvae double-stained for HRP (green) and $\operatorname{Brp}\left(B_{p}{ }^{\mathrm{NC} 82}\right.$ antibody, magenta). Scale bar, $20 \mu \mathrm{m}$. $\boldsymbol{B}$, High-magnification of a representative bouton ( $\boldsymbol{A}$, white square) of $+/+$, futsch $h^{K 68 / K 6}$, and futsch $h^{\mathrm{K} 68} /+$ larvae double-stained for HRP (green) and Brp (Brp ${ }^{\text {NC82 }}$ antibody, magenta). Scale bar, $2 \mu$ m. C, Quantification of total number of active zones at NMJs of control and futsch mutants: futsch mutants display a significant decrease of total Brp-positive active zones compared with controls. D, Quantification of the density of active zones in control and futsch mutants: there is a significant decrease of this density in futsch mutant genotypes compared with controls. Histograms show mean \pm SEM value, with the number of tested larvae indicated for each genotype. NS, Not significant; ${ }^{*} p<$ $0.05,{ }^{* *} p<0.01,{ }^{* * *} p<0.001$.

defect in active zone (AZ) number. We undertook this analysis by first looking at AZ number at muscles 6/7 NMJs. To that extent, we used the monoclonal antibody NC82, which recognizes the active zone protein Bruchpilot (Brp; Wagh et al., 2006). We observed a significant decrease of the total number of AZs in futsch mutants compared with their controls (Fig. 2A,C). Because AZs mostly localize within synaptic boutons, and because there was no consistent change in bouton number and size between all the studied genotypes, this suggested that the decrease in AZ number was the consequence of a decrease in AZ density within boutons. We tested this hypothesis by quantifying the number of AZs visible within the largest optical section of boutons of the same size [mean size of measured varicosities is futsch ${ }^{\text {K68/K68 }}: 13.8 \pm 0.2$ 

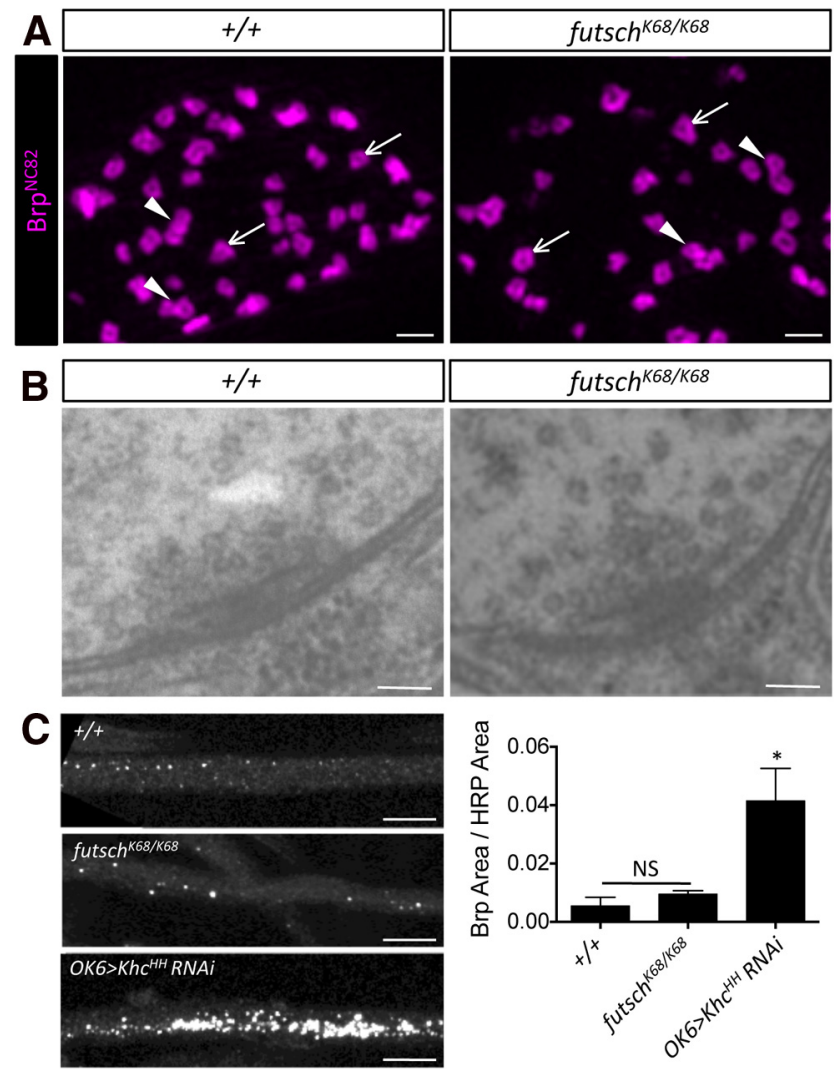

Figure 3. Normal transport of active zone material and normal shape of active zones in futsch mutants. A, 3D-SIM analysis of active zone shape (using Brp ${ }^{\mathrm{NC} 82}$ antibody) in control and futsch mutants. Isolated (arrows) and clustered (arrowheads) donut-shaped active zones are visible in both genotypes. Scale bars, $1 \mu \mathrm{m}$. $\boldsymbol{B}$, TEM analysis of active zones showed no structural difference between $+/+$ and futsch ${ }^{K 68 / K 68}$ mutants. Scale bars, $100 \mathrm{~nm}$. C, Brp ${ }^{\text {NC82 }}$ staining of larval segmental nerves of control, futsch mutants and larvae expressing motoneuronal-driven KHC RNAi (with OK6-Gal4). Axonal transport of Brp-positive material is not affected in futsch mutant compared with control. As a positive control, inhibition of KHC expression leads to accumulation of Brp-positive material in segmental nerves. This is quantified by measuring the total area of Brp staining in nerves relative to HRP stained nerve area. Scale bars, $10 \mu \mathrm{m}$. Histograms show mean \pm SEM values. NS, Not significant; ${ }^{*} p<0.05$.

$\mu \mathrm{m}^{2}(n=18)$ vs futsch ${ }^{K 68} /+: 13.2 \pm 0.2 \mu \mathrm{m}^{2}(n=16, p>0.05)$; futsch $^{K 68} / D f: 13.9 \pm 0.4 \mu \mathrm{m}^{2}(n=13)$ vs futsch ${ }^{K 68} /+: 13.2 \pm 0.2$ $\mu \mathrm{m}^{2}(n=16, p<0.01)$ or $D f l+: 13.1 \pm 0.3 \mu \mathrm{m}^{2}(n=12, p>$ $0.05)]$. We indeed observed a decrease in density of AZs in futsch mutants compared with controls (Fig. $2 B, D$ ). This shows that Futsch is required for normal density of Brp-positive AZs at the NMJ.

We further tested whether AZ shape and structure were normal in futsch mutants. To this aim, we used 3D-SIM. This superresolution microscopy doubles the resolution in each axis compared with confocal microscopy (experimentally measured resolution in the green channel $120 \times 120 \times 350 \mathrm{~nm}$ ). This virtually improves $3 \mathrm{D}$ resolution by a factor of 8 compared with classic wide-field microscopy, enabling to visualize the typical donut shape of AZs labeled with the $\operatorname{Brp}^{\text {NC82 }}$ antibody (Fig. $3 A$ ). This shape was first described using stimulated emission depletion microscopy (Kittel et al., 2006). Here, we could observe single, isolated AZs (Fig. 3A, arrows) and multiple, clustered active zones (Fig. $3 A$, arrowheads) as previously described in wild-type larvae (Kittel et al., 2006). There was no obvious difference in the donut shape of AZs in futsch mutants (Fig. 3A). We also tested whether there was a difference in the ratio of clustered versus isolated active zones between control and futsch mutants: we could not detect any significant difference in the proportion of multiple-AZ population between the two genotypes [ $\mathrm{futsch}^{\mathrm{K} 68 / \mathrm{K} 68}$ : $23.9 \pm 2.3 \%(n=6$ larvae; $>800$ AZs by larva $)$ vs $+/+: 21.3 \pm 1.0 \%$ $(n=6$ larvae; $>700$ AZs by larva, $p>0.05)]$. We also used transmission electron microscopy (TEM) to visualize whether the ultrastructure of AZs was normal in futsch mutants (Fig. 3B). We could detect normal electron-dense T-bars, and there was no significant change in the T-bar height as well as the platform and pedestal widths (Table 2). We also quantified the amount of vesicles around the AZs. There was no difference in the total amount of vesicles within $200 \mathrm{~nm}$ of the T-bar in futsch mutants compared with controls (Fig. 3B; Table 2). We counted the number of vesicles in contact with the plasma membrane underneath the T-bar. These vesicles are supposed to correspond to the pool of immediately releasable vesicles (Rizzoli and Betz, 2005). We could find fewer vesicles associated to the plasma membrane in futsch mutants, but this was not significant $(p=0.12$, Wilcoxon signed-rank test; Table 2). We also measured the distance between docked vesicles and the pedestal of the T-bar and selected the smallest distance. This distance is significantly increased in futsch mutants compared with control larvae (Table 2). Altogether, these results show that loss of Futsch leads to a decrease in AZ density, without any important alteration of AZ structure but possible changes in vesicle positioning with respect to the T-bar.

\section{Changes in AZ density in futsch mutants are not the consequence of altered microtubule cytoskeleton in axons and altered axonal transport}

Futsch is known to be a microtubule-binding protein, and as such, plays a role in microtubule organization within axons (Hummel et al., 2000) and synaptic terminals (Roos et al., 2000). Indeed, it was reported that futsch mutation causes a disorganization of the central microtubule bundle in NMJs (Ruiz-Canada et al., 2004) and an alteration of axonal transport of mitochondria (Bettencourt da Cruz et al., 2005). We hypothesized that the reduced density of AZs could be due to altered transport of active zone material along the axon in futsch mutants. We tested whether there was any alteration in axonal transport of AZ material (stained with Brp ${ }^{\mathrm{NC} 82}$ antibody) in futsch mutant nerves. Flies expressing an RNAi directed against the kinesin heavy chain (KHC), a molecular motor involved in anterograde trafficking (Hurd and Saxton, 1996) were used as positive controls of altered axonal transport. These flies display a high number of aggregated Brp-positive spots in the segmental nerves (Fig. 3C). In futsch mutants, we could not detect such aggregates, suggesting that there is no gross abnormality of active zone axonal transport [ratio of aggregates area relative to nerve area is $0.005 \pm 0.003$ for $+/+(n=4)$ vs futsch ${ }^{\mathrm{K} 68 / \mathrm{K} 68}: 0.009 \pm 0.001(n=6, p>0.05)$; Fig. $3 C]$. This result suggests that decreased active zone density in the futsch mutant NMJ is not the consequence of altered axonal transport of active zone material. We also tested whether partial disorganization of the microtubule cytoskeleton, as could be the case in the futsch mutant condition, could reproduce the decreased active zone density phenotype. We used RNAi directed against Tub84B, the main $\alpha$-tubulin subunit found in the nervous system. When expressing this Tub84B RNAi in motor neurons with the OK6-Gal4 driver, we could detect a reduction in bouton number and synaptic span, which is similar to the futsch mutant morphological phenotype (Fig. 4A; Table 1). However, quantification of the number of AZs revealed no difference with the control (Fig. 4A, C). Also, AZ density is not modified in presence of Tub84B RNAi (Fig. $4 B, C$ ). These data show that partial reduction of microtubule cytoskeleton has an impact on the NMJ 
Table 2. Quantification of T-bar size and vesicle positioning in control and futsch mutants

\begin{tabular}{|c|c|c|c|}
\hline T-bar architecture & Mean T-bar height (nm) & Mean T-bar platform width (nm) & Mean T-bar pedestal width (nm) \\
\hline$+/+(n=9)$ & $51 \pm 3$ & $157 \pm 20$ & $84 \pm 14$ \\
\hline futsch $^{K 68} / D f(n=12)$ & $53 \pm 5^{\mathrm{ns}}$ & $198 \pm 13^{\mathrm{ns}}$ & $101 \pm 14^{\mathrm{ns}}$ \\
\hline SVs distribution & Number of SVs within $200 \mathrm{~nm}$ of the T-bar pedestal & Number of SVs in contact with membrane and T-bar & $\begin{array}{l}\text { Mean smallest distance of membrane docked vesicle } \\
\text { to T-bar pedestal (nm) }\end{array}$ \\
\hline$+/+(n=9)$ & $14 \pm 2$ & $1.6 \pm 0.5$ & $72 \pm 8$ \\
\hline futsch $^{K 68} / D f(n=12)$ & $15 \pm 1^{\mathrm{ns}}$ & $1.2 \pm 0.3^{\mathrm{ns}}$ & $102 \pm 11^{*}$ \\
\hline
\end{tabular}

Measurements were made on TEM images obtained from two larvae of each genotype. Estimated parameters are described by Matkovic et al. (2013). ns, Not significant.

morphology, but no consequence on AZ density. This suggests that the effect of Futsch on AZ density is probably not the direct consequence of microtubule disorganization in the axon or at the neuromuscular junction. It also raises the possibility that Futsch could somehow have a more direct role with respect to AZs.

Futsch and MTs are both found at proximity of active zones but futsch is closer than MTs to active zones We explored this possibility by looking at Futsch localization around active zones, using again 3D-SIM. We performed double-staining of active zones (with monoclonal anti-Brp ${ }^{\mathrm{NC} 82}$ antibody) and Futsch (with polyclonal anti-Futsch ${ }^{\mathrm{N}-\text { term; }}$ Fig. 5A). We could detect Futsch ${ }^{\mathrm{N} \text {-term }}$ staining close to active zones ( $<200 \mathrm{~nm}$ distance) for $79 \pm 3 \%$ of active zones $(n=636$; 2 larvae). We measured the mean distance between the Futsch ${ }^{\mathrm{N} \text {-term }}$ peak of intensity and the Brp ${ }^{\mathrm{NC} 82}$ peak of intensity (along a selected line as shown in Fig. 5B) and found a mean distance of $\sim 35 \mathrm{~nm}(n=134 ; 2$ larvae). The histogram of distances reveals a colocalization between Futsch ${ }^{\mathrm{N} \text {-term }}$ and $\mathrm{Brp}^{\mathrm{NC} 82}$ staining in $40 \%$ of cases (i.e., a distance $<40 \mathrm{~nm}$, which is the pixel size; Fig.

$5 C)$. These results suggest that Futsch is actually found very close to most active zones. We further verified this using another polyclonal anti-Futsch antibody, which was directed against the C-terminal part of Futsch. Because the C-terminal part of Futsch protein is cleaved and is thought to interact with the N-terminal part of the protein (Halpain and Dehmelt, 2006; Zou et al., 2008), similar results should be obtained with both antibodies. This was indeed the case: we detected Futsch ${ }^{\mathrm{C} \text {-term }}$ staining close to active zones ( $<200 \mathrm{~nm}$ distance) for $91 \pm 3 \%$ of active zones $(n=1302$; 4 larvae). The mean distance between Futsch ${ }^{\mathrm{C} \text {-term }}$ peak of intensity and $\mathrm{Brp}^{\mathrm{NC} 82}$ peak of intensity was $\sim 40 \mathrm{~nm}$ ( $n=242$; 4 larvae; Fig. $5 B$ ) and the distribution of distances was identical to the one obtained with Futsch ${ }^{\mathrm{N} \text {-term }}$ stainings (Fig. 5C). This result confirms the fact that Futsch $\mathrm{N}$ - and C-term are found very close to most active zones. Because the anti-Futsch $22 \mathrm{C} 10$ and the antiBrp NC82 antibodies are monoclonal, we could not test the distance between the 22C10 epitope, which lays in the middle of Futsch protein sequence (Gögel et al., 2006) with respect to the $\mathrm{Brp}^{\mathrm{NC} 82}$ epitope. Therefore, we only measured the distance between 22C10 and Futsch N- or C-term epitopes. Taking into account the distance bias observed when using different dyes $(\sim 15 \mathrm{~nm})$ we found a distance ranging from 35 to $50 \mathrm{~nm}$ between 22C10 and Futsch N- or C-term epitopes (Fig. 6).

Altogether, these results show for the first time that Futsch is very close to most active zones at the NMJ. This suggests that Futsch may indeed have a local role with respect to active zones. Knowing that Futsch is a microtubule binding protein, we then wondered whether microtubules were also found close to active zones. We tested this hypothesis by performing double staining of active zones (with anti-Brp ${ }^{\mathrm{NC} 82}$ antibody) and tubulin (polyclonal ATN02 or ab15246). We could also find microtubules close to active zones $(<200 \mathrm{~nm}$ distance) for $91 \pm 1 \%$ of the studied active zones (Fig. $5 A, B ; n=817 ; 4$ larvae). The histogram of distances reveals a colocalization between MTs and Brp ${ }^{\text {NC82 }}$ peaks of intensity in $20 \%$ of cases (Fig. $5 C$ ). The mean distance between MTs and active zones was $\sim 55 \mathrm{~nm}(n=227 ; 2$ larvae). Because the same dye combination was used in $\mathrm{Brp}^{\mathrm{NC} 82} /$ tubulin staining and $\mathrm{Brp}^{\mathrm{NC} 82} /$ Futsch staining, we could compare the distances (Fig. 5C): our results suggest that $\mathrm{Brp}^{\mathrm{NC} 82} /$ tubulin distance is higher than $\mathrm{Brp}^{\mathrm{NC} 82} /$ Futsch $\mathrm{N}$-or $\mathrm{C}$ terminus distance. In conclusion, these results using $3 \mathrm{D}$ super-resolution microscopy show that both Futsch and MTs are both found in the vicinity of active zones. 

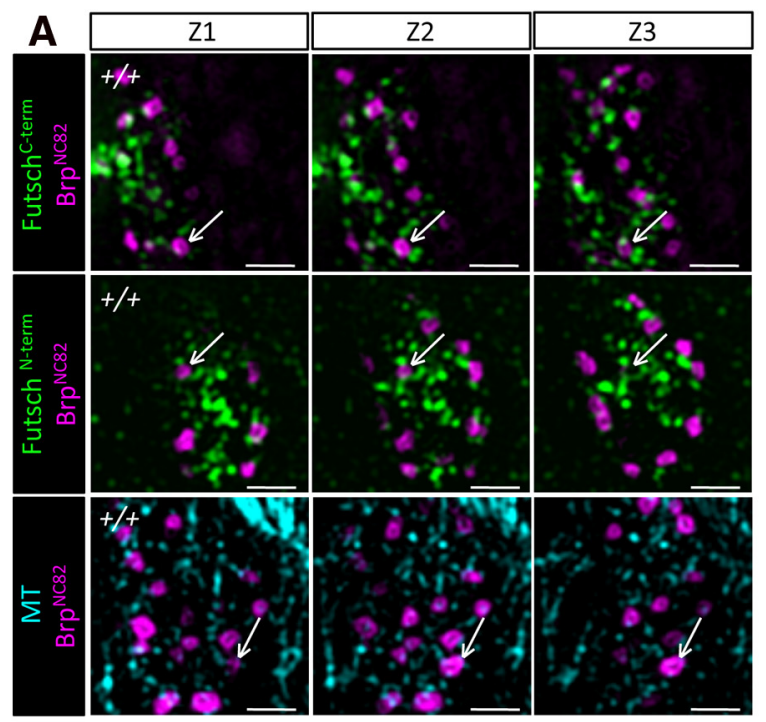

B
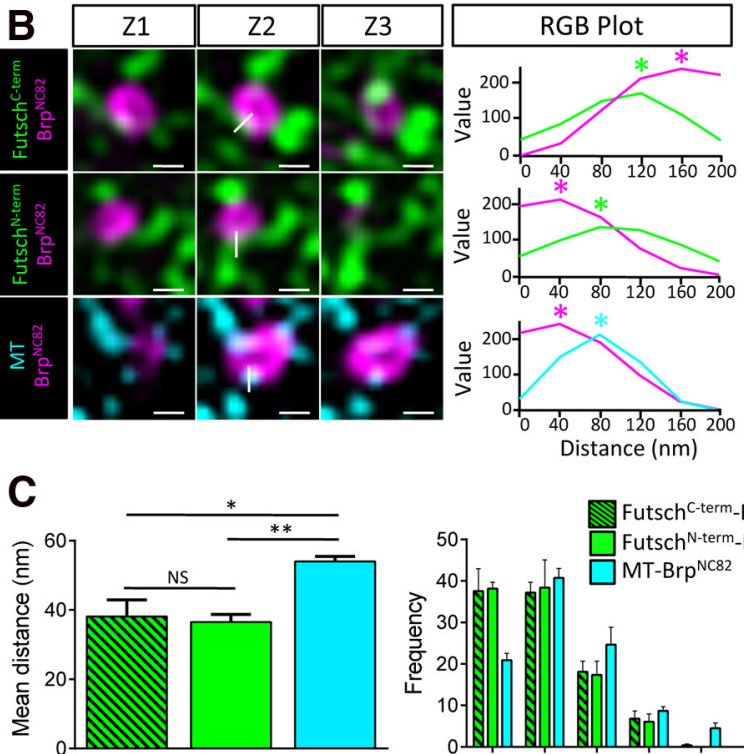

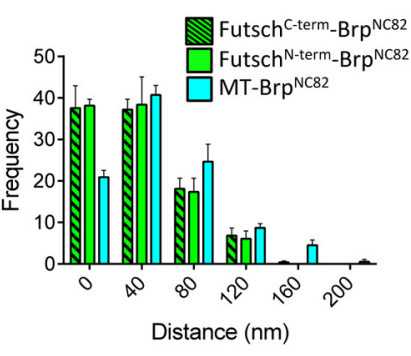

Figure 5. Spatial relationships between active zones, Futsch and MTs. $A$, Three adjacent 3D-SIM z-sections (125 nm apart) of control NMJ boutons double-stained for Futsch ${ }^{\text {-term }}$ and $\mathrm{Brp}^{\mathrm{NC} 82}$ (top row), Futsch ${ }^{\mathrm{N}-\mathrm{term}}$, and Brp ${ }^{\mathrm{NC} 82}$ (middle row) or tubulin and Brp ${ }^{\mathrm{NC82}}$ (bottom row). Arrows indicate AZ shown at higher-magnification in $\boldsymbol{B}$. Scale bars, $1 \mu \mathrm{m}$. B, Highermagnification of three adjacent 3D-SIM z-sections of Brp-positive active zones double-stained for Futsch ${ }^{\text {-term }}$ (top row), Futsch ${ }^{\mathrm{N} \text {-term }}$ (middle row), or tubulin (bottom row). Scale bars, 0.2 $\mu \mathrm{m}$. White lines on selected active zones are the ones used for the RGB profile plots shown beside. The RGB profile plots show the relative position of the different peaks of stainings (peak is labeled with an asterisk). The selected active zones correspond to the most representative situation, with a distance of $40 \mathrm{~nm}$ (one pixel) between the two peaks of staining intensity ( $\boldsymbol{C}$, see histogram of distances). C, Quantification of the mean distance between Futsch and Brp peaks of staining intensity or MT and Brp peaks of staining intensity, as measured with profile plots. Mean distance between Futsch (either C-term or N-term stainings) and Brp is significantly smaller than the mean distance between MT and Brp. Diagram of distribution show that $40 \%$ of Brp-positive active zones colocalize with Futsch staining (either C-term or N-term).

Futsch is not responsible for MT anchoring to active zones What is the relative function of Futsch and microtubules around active zones? One possibility is that Futsch anchors microtubules near active zones, which would stabilize these active zones and control their density. We tested whether Futsch is important in controlling MT distance with respect to active zones by looking at
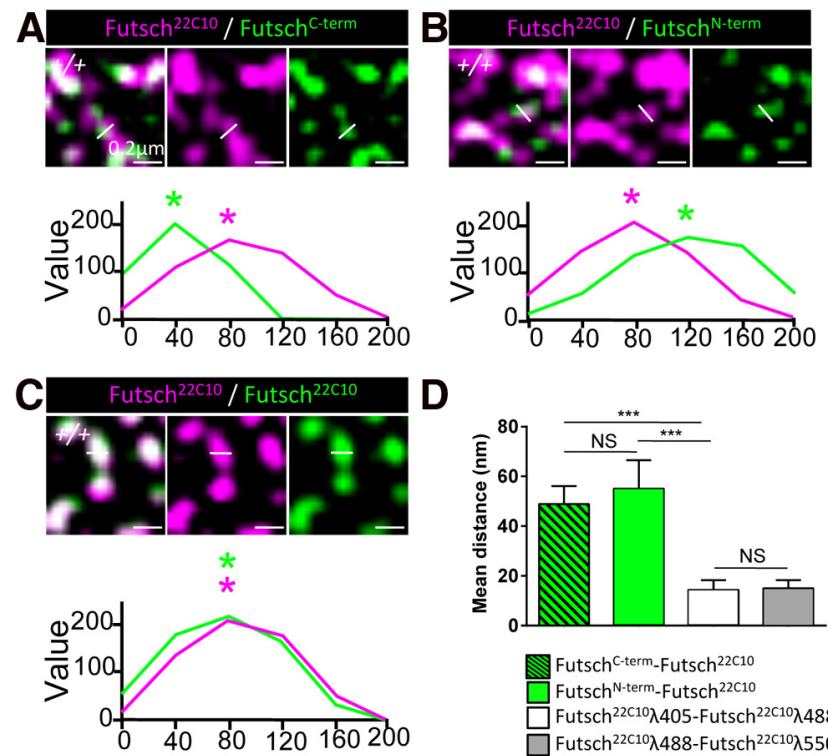

D



Figure 6. Distance between Futsch 2210 and Futsch ${ }^{\text {N-term }}$ of Futsch ${ }^{\text {C-term }}$ epitopes. $\boldsymbol{A}, \boldsymbol{B}$, High-magnification image of control $(+/+)$ NMJ boutons double-stained for Futsch ${ }^{2210}$ (magenta) and Futsch ${ }^{\text {C-term }}$ (green) in $\boldsymbol{A}$, or Futsch ${ }^{\mathrm{N} \text {-term }}$ (green) in $\boldsymbol{B}$. Representative RGB profile plots show that the two peaks are shifted apart. $C$, High-magnification of control NMJ boutons stained for Futsch ${ }^{22 C 10}$ with two secondary antibodies carrying the two dyes used in $\boldsymbol{A}$ and $\boldsymbol{B}$ (AlexaFluor 488 and CFL 405). Representative RGB plot shows that the two peaks of staining strongly colocalize. This indicates that the distance between the two peaks observed in $\boldsymbol{A}$ and $\boldsymbol{B}$ is not just the consequence of using secondary antibodies with different dyes. $\boldsymbol{D}$, Mean distances measured in the conditions described in $\boldsymbol{A}$ and $\boldsymbol{B}\left(n=27\right.$ for Futsch ${ }^{\mathrm{C} \text {-term }} ; n=16$ for Futsch $\left.{ }^{\mathrm{N} \text {-term }}\right)$, and in the conditions described in C (two different dye combinations were tested: $n=25$ for the combination AlexaFluor 488 and CFL 405; $n=48$ for the combination AlexaFluor 488 and Cy3). Scale bar, $0.2 \mu \mathrm{m}$. Histograms show mean \pm SEM values. NS, Not significant; ${ }^{* * *} p<0.001$.

MT-active zones distance in futsch mutants, using 3D-SIM. We could not detect any change in this distance (Fig. 7A). The mean MT-Brp distance in futsch mutants was $\sim 55 \mathrm{~nm}$ and the distance distribution was virtually identical to the one observed in wildtype NMJ [mean MT-Brp distance $+/+: 54 \mathrm{~nm}(n=227 ; 3$ larvae) vs futsch ${ }^{\mathrm{K} 68 / \mathrm{K} 68}: 53 \mathrm{~nm}(n=196 ; 3$ larvae); Fig. $7 B, C]$. Similarly, the percentage of AZs with MTs nearby $(<200 \mathrm{~nm}$ distance) was unchanged in futsch ${ }^{\mathrm{K} 68 / \mathrm{K} 68}$ mutants: $92 \pm 1 \%(n=$ 861; 3 larvae). This indicates that MT distance to active zones does not depend on Futsch. This also indicates that other protein components than Futsch must be responsible for MT localization close to AZs. We thus tested an alternative hypothesis, which is that Futsch may itself anchor to microtubules and contribute to active zone stabilization by providing an additional "link" between active zones and microtubules.

\section{Relative localization of futsch and microtubules around active zones}

We tested this new hypothesis by performing triple-staining and looking at respective localization of MTs and Futsch around active zones, using 3D-SIM. As expected, MTs and Futsch were found to colocalize at the level of the central microtubule bundle in the synaptic terminal (data not shown). For AZ analysis, we selected active zones oriented tangentially to the imaging axis such as to see their donut shape. We first tested how frequently the Futsch protein is found close to the MTs that are contacting the active zones. When looking at all MT contact points with AZs ( $n=48$ for $16 \mathrm{AZs}$ ), we could observe a colocalization with Futsch $^{\mathrm{N} \text {-term }}$ in $86 \pm 1 \%$ of cases ( $n=33$ AZs; 2 larvae), as illustrated with white pixels in Figure 8. Similarly, when look- 



Figure 7. Futsch is not responsible for MT anchoring to AZ. A, Three adjacent 3D-SIM $z$-sections (125 nm apart) of NMJ boutons double-stained for tubulin (cyan) and Brp (Brp NC82 antibody, magenta) in futsch mutant larvae. Arrows indicate AZ shown at higher-magnification underneath. Scale bar, $1 \mu \mathrm{m}$. $\boldsymbol{B}$, Higher-magnification of three adjacent 3D-SIM z-sections of Brp-positive active zones double-stained for tubulin (cyan). Scale bars, $0.2 \mu \mathrm{m}$. White lines are the ones used for the RGB profile plots shown beside. C, Quantification of the mean distance between MT and Brp peaks of staining intensity in control and futsch ${ }^{K 68 / K 68}$ mutants. Mean distance between MT and Brp does not significantly change in futsch mutant (NS, non significant). Similarly, diagram of distance distribution shows no change between control futsch ${ }^{K 68 / 668}$ mutants.

ing at the contact points of Futsch ${ }^{\mathrm{N} \text {-term }}$ with $\mathrm{AZs}$, we could observe a colocalization with MTs in $80 \pm 4 \%$ of cases. This indicates that Futsch ${ }^{\mathrm{N} \text {-term }}$ and MTs partially colocalize around active zones.

We further looked at the respective localization of MTs and Futsch $^{\mathrm{N} \text {-term }}$ peaks of intensity. When focusing on the contact points between MTs and AZ in which Futsch ${ }^{\mathrm{N} \text {-term }}$ staining was detected, the peak of Futsch ${ }^{\mathrm{N} \text {-term }}$ staining intensity was in between MTs and AZs in $68 \pm 9 \%$ of cases (Fig. $8 A, B, E, F$ ). This indicates that Futsch ${ }^{\mathrm{N} \text {-term }}$ is most often found in between MTs and AZs. We could detect a colocalization of Futsch ${ }^{\mathrm{N} \text {-term }}$ and MTs peaks of staining intensity in $17 \pm 8 \%$ of cases (Fig. $8 C, E$ ) and Futsch ${ }^{\mathrm{N} \text {-term }}$ peak of staining being away from MTs and AZs in $14 \pm 2 \%$ of cases (Fig. $8 D, E$ ). We obtained the same results when performing stainings with an antibody directed against Futsch C-term (Fig. 8E).

Altogether, our results show that Futsch and microtubule stainings importantly overlap nearby active zones, and that Futsch is often found in an intermediate position between microtubules and Brp-labeled active zones. This supports the idea of Futsch playing a stabilizing role as a linker between active zones and microtubules. This also suggests that Futsch may directly interact with some protein components of the active zones.

Futsch, but not MTs can directly interact with active zone components

We tested whether Futsch could directly interact with active zone components, by using the PLA. This assay enables to detect
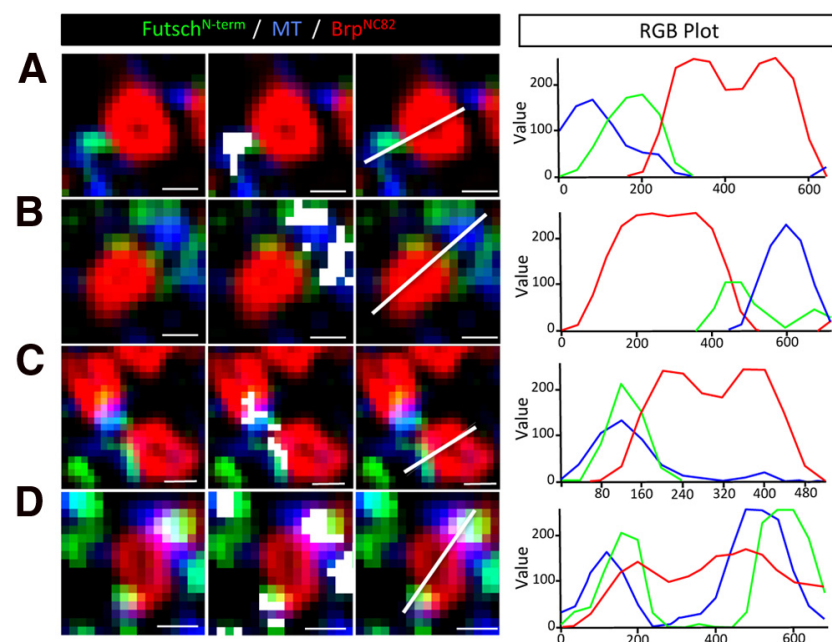

E


$\mathbf{F}$

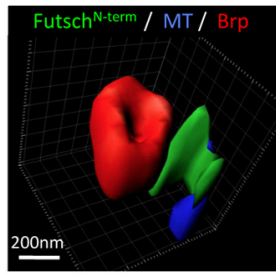

Figure 8. Respective localization of Futsch and MTs nearby AZs. $A-D$, Four different active zones are shown in each line. The four images are one $z$-section obtained by 3D-SIM on a

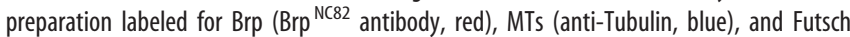
( $\mathrm{N}$-term antibody, green). The first column corresponds to the RGB image of active zones. The second column shows the same images with the pixels for which there is colocalization of Futsch and MTs in white (as measured with the colocalization plugin of ImageJ): Futsch and MTs strongly colocalize nearby AZs. The third column indicates the position of the line along which is drawn the RGB plot shown in the fourth column. The left side of the RGB plot corresponds to the left end of the transecting line. $\boldsymbol{A}, \boldsymbol{B}$, The Futsch peak is found in between the MTs and Brp peaks of staining (two examples of this situation are shown because it is the most frequent one). $C$, The Futsch peak of intensity is at the same position as MTs peak of intensity. $D$, On the left of the RGB plot, Futsch peak of intensity is found in-between MTs and Brp peaks of intensity, like $\boldsymbol{A}$ and $\boldsymbol{B}$. On the right, Futsch peak of intensity is further away from the active zone and it is the MTs peak of intensity that is in-between Futsch and Brp peaks of intensity. Scale bars, $0.2 \mu \mathrm{m}$. E, Histogram of the relative frequencies in percentage of the three different situations found (mean \pm SEM values): Futsch peak of staining in between MTs and Brp, MTs peak of staining in between Futsch and Brp, and MTs and Futsch colocalizing. Data are shown for stainings with Futsch ${ }^{\text {N-term }}$ ( $n=33 \mathrm{AZs} ; 2$ larvae) and Futsch ${ }^{\mathrm{C} \text {-term }}(n=17 \mathrm{AZs} ; 2$ larvae) antibodies. In both cases, the frequency of Futsch in between MT and Brp is significantly higher than the frequency of MTs found in between Futsch and Brp. NS, Not significant; ${ }^{* *} p<0.01$. $\boldsymbol{F}$, 3D reconstruction of the active zone shown in $\boldsymbol{A}$.

protein-protein interactions between endogenous proteins in situ. It is based on immunocytochemistry with two primary antibodies targeting the tested proteins. The secondary antibodies are conjugated with oligonucleotides, which can be ligated together if they are close enough $(<40 \mathrm{~nm})$. The ligated DNA is detected by in situ PCR amplification with fluorescent nucleotides, resulting in colored spots at the position where the interaction takes place. This assay was reported to give equivalent results compared with coimmunoprecipitation with the advantage of subcellular localization detection of a direct protein-protein interaction (Graf et al., 2011; Vizlin-Hodzic et al., 2011). Here, we first tested interactions between Futsch and Brp, as well as MTs and Brp. We double-stained the NMJ with anti-HRP antibody to be able to localize these interactions. As a positive control, we first tested whether we could detect a PLA signal between Futsch and 


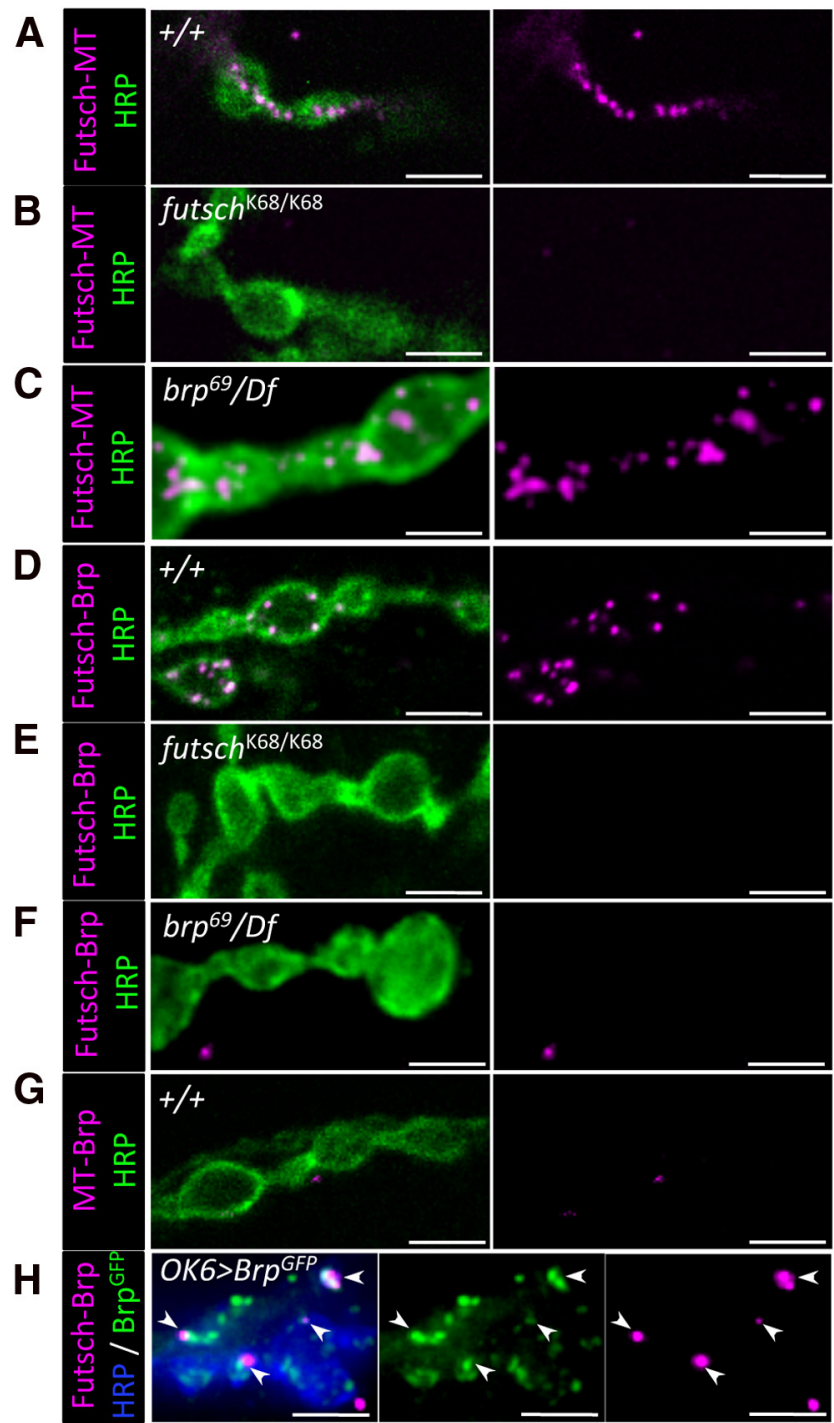

Figure 9. Futsch, but not MTs, physically interacts with active zone components. $A-E$, Detection of protein-protein interactions using PLA assay at muscle 6/7 NMJs of wandering third instar larvae. $\boldsymbol{A}-\boldsymbol{C}$, MTs (labeled with DM1A antibody) and Futsch ${ }^{\mathrm{N} \text {-term }}$ interactions visualized with PLA (magenta) with a HRP costaining (green) in control $(\boldsymbol{A})$, futsch $\mathrm{h}^{\mathrm{K} 68 / \mathrm{K} 68}$ mutant $(\boldsymbol{B})$, and $b r p^{69} / D f(2 R) B S C 29$ mutant (C. D $-\boldsymbol{F}$, Futsch ${ }^{\mathrm{N}-\operatorname{term}}$ and Brp ${ }^{\mathrm{NC} 82}$ interactions visualized with PLA (magenta) with a HRP costaining (green) in control (D), futsch ${ }^{K 68 / K 68}$ mutant (E), and $b r p^{69}$ / Df(2R)BSC29 mutant $(\boldsymbol{F}) . \mathbf{G}$, Absence of MTs (labeled with ab15246 antibody) and Brp ${ }^{\mathrm{NC} 82}$ interaction, as visualized with PLA (magenta) with a HRP costaining (green) in control larvae. $\boldsymbol{H}$, Futsch ${ }^{\mathrm{C}-\text { term }}$ and $\mathrm{Brp}^{\mathrm{N} C 82}$ interaction visualized with PLA (magenta) in larvae overexpressing Brp-GFP protein (green). HRP costaining is shown in blue. PLA spots (arrows) within the boutons are all found nearby Brp-GFP spots. $\boldsymbol{A}, \boldsymbol{B}, \boldsymbol{D}, \boldsymbol{E}, \mathbf{G}$ Confocal images (one $1 \mu \mathrm{m} z$-section). Scale bars, $5 \mu \mathrm{m}$.

Table 3. PLA results for different antibody combinations in control larvae

\begin{tabular}{|c|c|c|c|c|}
\hline Mouse & MT (ab15246) & Futsch $^{\mathrm{N} \text {-term }}$ & Futsch ${ }^{\text {--term }}$ & Brp $^{N-\text { term }}$ \\
\hline MT (DM1A) & & + & + & - \\
\hline Futsch 22110 & + & & & + \\
\hline $\mathrm{Brp}^{\mathrm{NC} 82}$ & - & + & + & \\
\hline
\end{tabular}

+ , Indicates a positive result; - , indicates a negative result.

MTs, which are known to biochemically interact. Using two different antibody combinations (Fig. 9A; Table 3), we could indeed observe a PLA signal at the NMJ. This signal was localized at the position of the microtubule bundle in the middle of varicosities, in accordance with the localization of Futsch and the microtu-
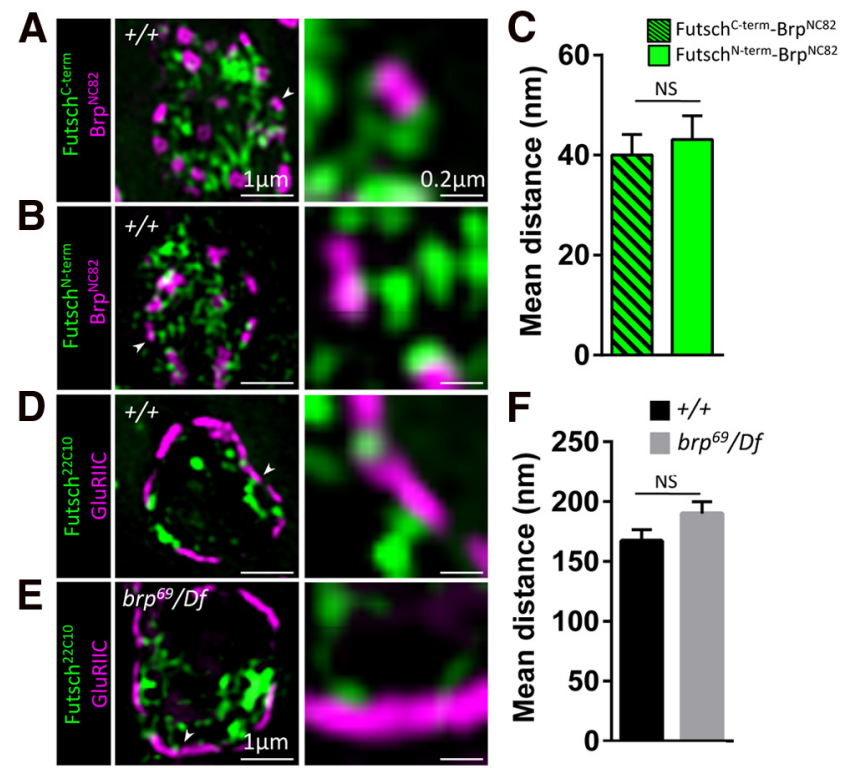

Figure 10. Localization of Futsch with respect to synapses in control larvae and brp mutants. $\boldsymbol{A}, \boldsymbol{B}$, Futsch $^{\mathrm{C}-\text { term }}$ (green; $\boldsymbol{A}$ ) and Futsch ${ }^{\mathrm{N}-\text { term }}$ (green; $\boldsymbol{B}$ ) localization with respect to Brp ${ }^{\mathrm{NC} 2}$ (magenta), when looking at synapses oriented transversally to the optical sections (arrows) in control larvae. A higher-magnification is shown in the right. $C$, Mean distances measured on synapses oriented this way $\left(n=62\right.$ from 2 larvae for Futsch ${ }^{\mathrm{C} \text {-term }}$ and $n=51$ from 2 larvae for Futsch $\left.{ }^{\mathrm{N} \text {-term }}\right)$. They are similar for the two types of staining and correspond to what was previously measured on tangential optical sections of synapses $(\sim 40 \mathrm{~nm}) . D, E$, Futsch ${ }^{2210}$ (green) localization with respect to DGluRIIC (magenta) in control $(+/+)$ and brp mutant $\left(b r p^{69} /\right.$ $D f(2 R) B S(29)$ larvae. Examples of synapses oriented transversally are labeled by arrows and shown at higher-magnification in the right. $\boldsymbol{F}$, Mean distances measured on synapses oriented this way ( $n=77$ from 2 larvae for $+1+$ and $n=65$ from 2 larvae for brp mutant). There is no significant difference between control and brp mutants. Scale bars: left, $1 \mu \mathrm{m}$; right, $0.2 \mu \mathrm{m}$. Histograms show mean \pm SEM values. NS, Not significant.
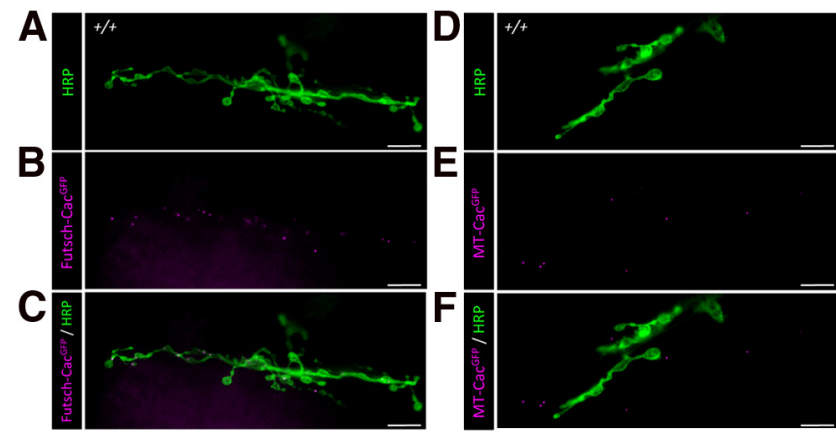

Figure 11. PLA results for Futsch or microtubules and GFP-cacophony. $\boldsymbol{A}-\boldsymbol{C}$, Futsch and GFP-cacophony interaction visualized with PLA (magenta) with a HRP costaining (green) in control larvae. $\boldsymbol{D}-\boldsymbol{F}$, Absence of MT and GFP-cacophony interaction, as visualized with PLA (magenta) and a HRP costaining (green) in control larvae. The antibodies used are polyclonal anti-GFP (Invitrogen, A-6455), anti-Futsch 22C10 antibody and monoclonal anti-Tubulin antibody (DM1A). The images were obtained with wide-field fluorescence microscopy, illustrating that the PLA signal is easily visible with this technique. Scale bar, $20 \mu \mathrm{m}$.

bules within varicosities (Fig. 9A). We could also see that there was no PLA signal in these conditions in $\mathrm{futsch}^{\mathrm{K68/K68}}$ mutant larvae, which demonstrated that the observed signal was specific for the Futsch protein (Fig. 9B). As another control, this signal was not affected in brp mutants (Fig. 9C). We then tested whether we could detect a PLA signal between Futsch and Brp and between MTs and Brp. For each tested interaction, we used two different antibodies for each protein to avoid any nonspecific effect of one particular antibody (Fig. $8 F$ ). We could detect a PLA 
signal between Futsch and Brp (Fig. 9D). This signal was localized at the periphery of the varicosities, in accordance with the localization of active zones. This signal was dependent on the presence of the Futsch and the Brp proteins since it was absent in futsch ${ }^{\mathrm{K} 68 / \mathrm{K} 68}$ and $b r p^{69} / D f(2 R) B S C 29$ mutants respectively (Fig. 9E,F). Interestingly, we could never detect a PLA signal between MTs and Brp protein (Fig. 9G) despite the use of two different antibody combinations. The positive and negative results with the different antibody combinations tested are summarized in Table 3 . We further verified that positive Futsch-BRP PLA spots were actually found nearby active zones, by performing PLA in larvae overexpressing a GFP-tagged Brp protein to label active zones. The PLA-positive spots colocalized with GFP-labeled active zones, confirming the localization of the Futsch-Brp signal at the proximity of active zones (Fig. $9 \mathrm{H}$ ). Altogether, these data show that Futsch is close enough to active zone Brp protein so that it can physically interact with it, whereas MTs cannot.

To test whether Brp was the direct interactor of Futsch at the active zone, and whether it was required for Futsch localization close to active zones, we looked at Futsch localization in brp mutants. In the absence of Brp, we labeled synapses using an antibody directed against postsynaptic glutamate receptors (anti-DGluRIIC) and measured distances on synapses oriented transversally to the optical sections. Note that Futsch-Brp distances measured this way were similar $(\sim 40 \mathrm{~nm})$ to those measured using tangential sections in control larvae (Fig. 10 A,D, compare with Fig. 5). Although not significantly different, Futsch ${ }^{22 \mathrm{C} 10}$-GluRIIC distance was found to be larger $(\sim 190 \mathrm{~nm}$; $n=65,2$ larvae, $p=0.09$ ) in brp mutants than in control larvae $(\sim 165 \mathrm{~nm} ; n=77,2$ larvae; Fig. $10 B-D)$. In addition the number of Futsch-positive synapses was not significantly modified in $b r p$ mutants: $76 \pm 2 \%(n=103$; 2 larvae $)$ of receptor fields had Futsch $^{\mathrm{N} \text {-term }}$ staining nearby (distance $<360 \mathrm{~nm}$ ) in control larvae, compared with $70 \pm 2 \%(n=95 ; 2$ larvae; $p=0.16)$ in $b r p$ mutants. This indicates that Brp protein is not required for Futsch localization at close proximity to active zones and is probably not the direct interactor of Futsch at this place. Another active zone component may be a direct interactor of Futsch and may be mislocalized in the absence of Brp, which could explain the slight increase in distance we observed in brp mutants. We confirmed this hypothesis using PLA: a PLA signal was obtained between Futsch and GFP-tagged overexpressed Cacophony $\mathrm{Ca}^{2+}$ channels (Fig. 11A-C), but not between MTs and these channels (Fig. $11 D-F$ ). This suggests that Futsch is actually in a position to physically interact with another active zone component, Cacophony $\mathrm{Ca}^{2+}$ channels.

Altogether, these results indicate that Futsch is in a position to directly interact with some active zone components. This further strengthens our model of Futsch playing a local stabilizing role on active zones, by reinforcing their link with nearby microtubules.

\section{Discussion}

\section{Electrophysiological phenotypes of futsch mutants}

Our study was aimed at understanding the presynaptic physiological function of Futsch. To that end, we used different genetic conditions with the fusch ${ }^{K 68}$ allele: either homozygous or transheterozygous with a deficiency encompassing the futsch gene.
Our work did show a $\sim 50 \%$ decrease of quantal content at the NMJ of futsch mutants. This decrease may be due to a decrease in the probability of vesicle release. We tested this by looking at changes in presynaptic $\mathrm{Ca}^{2+}$ dynamics. Our electrophysiological results indicated no change in paired-pulse facilitation (PPF), no change in the shape of eEJCs and no change in the slope of the $\mathrm{Ca}^{2+}$ response between 0.2 and $0.45 \mathrm{mM} \mathrm{Ca}^{2+}$. This set of results speaks against a change in vesicle release probability.

We then considered whether the reduced release could be due to a decrease in the number of release sites. We found a significant $20-30 \%$ decrease in total number of AZs without any significant change in the number of docked vesicles in futsch mutants. Moreover, TEM data showed a significant increase in the distance of docked vesicles to the base of the T-bar. Knowing that voltagedependent $\mathrm{Ca}^{2+}$ channels are concentrated at this place (Fouquet et al., 2009), and that the extent of the $\mathrm{Ca}^{2+}$ influx depends on the extracellular $\mathrm{Ca}^{2+}$ concentration (Oheim et al., 2006; Thanawala and Regehr, 2013), it is possible that distant docked synaptic vesicles in futsch mutants are less easily reached by the $\mathrm{Ca}^{2+}$ influx. This could explain the reduced release observed in low $\mathrm{Ca}^{2+}$ concentrations in futsch mutants. RRP measurements did not show a significant difference between control and futsch mutants. This apparent discrepancy may result from the measurement method that required high extracellular $\mathrm{Ca}^{2+}$ and therefore excess of security level for neurotransmission that could mask the defect in release process in futsch mutants. Taking this into account, one tentatively suggests that the observed reduced release in futsch mutants results from a reduced pool of releasable vesicles.

\section{Microtubules and the reduced number of AZs}

To better understand the mechanisms underlying AZ number decrease in futsch mutants, we focused on the known effect of MAP1/Futsch in stabilizing microtubules (Ruiz-Canada et al., 2004) and searched for a correlation between the futsch phenotype and what happens when the number of microtubules is affected. We first looked at the fusch ${ }^{K 68}$ morphological phenotype. In accordance with previously published work (Gögel et al., 2006), we could find that loss of futsch induced a decrease in synaptic span. However, there was no consistent effect with respect to the decrease in bouton number. This morphological phenotype was thought to be the consequence of the disruption of the microtubule bundle within the boutons (Ruiz-Canada et al., 2004). Here, we further prove this hypothesis by showing that mild disruption of the MT cytoskeleton (with motoneurondriven $\mathrm{RNAi}$ ) also leads to a decrease in synaptic span, as well as a reduction in the number of boutons. This confirms that the control of NMJ synaptic span by Futsch occurs via an action of Futsch with respect to microtubules. 
However, when considering the number of AZs, two set of data show that this effect is not the consequence of a MT-stabilizing or organizing function of Futsch. Indeed, in tubulin-RNAi experiment in which there is a clear morphological phenotype, we could not detect a significant effect onto AZ density, indicating that this parameter is more resistant to MT disruption than NMJ growth and shape. Also, in futsch mutants, there was no change in the mean distance of MTs with respect to AZs, suggesting that Futsch does not play a role in organizing the MT cytoskeleton at this place.

These data indicate that Futsch regulation of AZ number/ density implicates molecular mechanisms that are different from just the regulation of MT stability. These may involve a linkage function of MAP1/Futsch between the MT cytoskeleton and AZ components.

\section{Multicolor super-resolution microscopy and respective localization of futsch, microtubules and AZs}

3D-SIM was first used at the Drosophila NMJ to study the relative localization of Futsch and ankyrin (Pielage et al., 2008). Here, we used this technology to analyze the localization of Futsch and microtubules around AZs. Our results show for the first time that MAP1/Futsch and microtubules are actually very close to AZs, and that MAP1/Futsch is intermediate between AZs and MTs. The fact that MAP1 proteins play an intermediate function at the synapse is not new when considering the postsynapse. Indeed, it was shown that MAP1S and MAP1B directly interact with NR3A subunit of NMDA receptors (Eriksson et al., 2007, 2010), and that MAP1A directly interacts with scaffolding proteins PSD93 (Brenman et al., 1998) and PSD95 (Ikeda et al., 2002; Reese et al., 2007), suggesting a function of the microtubule cytoskeleton in postsynaptic receptor field stability. However, the intermediate positioning of MAP1 proteins with respect to receptors/scaffolding proteins and microtubules was never studied in detail. Here, the use of super-resolution microscopy allowed to show that Futsch is found in-between MTs and AZs. Although the difference in distance $(\sim 20 \mathrm{~nm})$ between Futsch and MTs with respect to AZs is small, it is confirmed by our PLA results.

When analyzing Futsch localization with respect to MTs and $\mathrm{AZs}$, we used two different polyclonal antibodies directed against the N- and C-terminal ends of Futsch. Similar results were obtained with both antibodies confirming previous data indicating that Futsch ${ }^{\mathrm{C}-\text { term }}$ is cleaved and very likely binds to Futsch ${ }^{\mathrm{N} \text {-term }}$ region (Zou et al., 2008). The simplest interpretation of our results is that Futsch ${ }^{\mathrm{N} \text {-term }}$ (and the associated Futsch ${ }^{\mathrm{C} \text {-term }}$ fragment) is at a $\sim 40 \mathrm{~nm}$ distance from $\mathrm{Brp}^{\mathrm{NC} 82}$ epitope. The relative localization of the remaining domain of the Futsch protein with respect to $\mathrm{Brp}^{\mathrm{NC} 82}$ epitope is an open question that requires the use of additional polyclonal antibodies that are not available yet. Still, we were able measure the mean distance between Futsch $^{22 \mathrm{C} 10}$ epitope to Futsch ${ }^{\mathrm{N} \text {-term }}$ epitope $(35-50 \mathrm{~nm})$. This indicates that 3D-SIM enables the study of the relative localization of protein domains within the cell. This also suggests that Futsch ${ }^{22 \mathrm{C} 10}$ epitope is not far away from AZs as well. This is confirmed by our PLA results, because a positive PLA signal was obtained with Futsch ${ }^{22 \mathrm{C} 10}$ antibody and anti-Brp ${ }^{\mathrm{N} \text {-ter }}$ polyclonal antibody.

Finally, we found a distance of $\sim 165 \mathrm{~nm}$ between Futsch and postsynaptic glutamate receptors, which is in accordance with a previously estimated distance of $\sim 155 \mathrm{~nm}$ between Brp ${ }^{\text {NC82 }}$ epitope and glutamate receptors (Fouquet et al., 2009).

\section{Futsch interacts with active zones components}

PLA is a technique (Söderberg et al., 2006) increasingly used to show that proteins belong to a common protein complex. Compared with coimmunoprecipitation this technique has the advantage to show where the protein complex localizes within the cell (Graf et al., 2011; Vizlin-Hodzic et al., 2011). Here, we use for the first time this technique on the larval Drosophila NMJ preparation. We confirmed previous molecular and biochemical studies about Futsch-MT interaction, and show that these interactions mostly occur within the central microtubule bundle. We also verified that we could not detect these interactions in futsch mutants. Surprisingly, we could not see Futsch-MT interactions at the periphery of synaptic boutons. The explanation may be that they represent such a small percentage compared with the ones existing within the bundle, that they are not detectable with this technique. Here, we show that Futsch is in a position to interact with Brp and Cacophony channels, which are members of the active zone protein complex. Analysis of brp mutants suggests that Brp is not required for Futsch localization close to AZs, and thus, may not be the only direct interactor of Futsch at the AZs. A direct interaction between Futsch and Cacophony calcium channels may exist. The LC2 chain, resulting from the cleavage of MAP1A protein, can physically interact with the calcium channel $\alpha$-subunit $\mathrm{Ca}_{\mathrm{V}} 2.2$ in mouse (Leenders et al., 2008). However, the 23 amino-acid domain of $\mathrm{Ca}_{\mathrm{V}} 2.2$ that binds LC2 and that is required for the LC2- $\mathrm{Ca}_{\mathrm{V}} 2.2$ interaction is not present in Cacophony, the Drosophila homolog of $\mathrm{Ca}_{\mathrm{V}} 2$ family subunits. This suggests that there is no such direct interaction between Futsch and Cacophony. This is further confirmed by a thesis work showing no change in Cacophony localization and concentration at Drosophila NMJs in some futsch mutants (Zou, 2007). Further work is required to conclude about the existence of direct interactions between Futsch and Brp or Cacophony. The positive PLA signals between Futsch ${ }^{\mathrm{N}-t e r m}$ and $\mathrm{Brp}^{\mathrm{NC} 82}$ (epitope most distal to the plasma membrane; Fig. 12 ), as well as between Futsch ${ }^{22 \mathrm{C} 10}$ and Brp $^{\mathrm{N} \text {-term }}$ (close to the plasma membrane) or Cacophony, suggest that Futsch protein is oriented perpendicular to the T-bar axis (Fig. 12). Moreover, this also suggests an intermediate position of Futsch between the base and the extremity of the AZ.

In conclusion, our work highlights the importance of MAP1/ Futsch in regulating active zone density and neurotransmitter release and shows that Futsch interconnects microtubules and active zones. Together with other works showing the importance of MAP1 interactions with postsynaptic proteins, this work further emphasizes the role of MAP1 proteins in synaptic organization and function.

\section{References}

Bettencourt da Cruz A, Schwärzel M, Schulze S, Niyyati M, Heisenberg M, Kretzschmar D (2005) Disruption of the MAP1B-related protein FUTSCH leads to changes in the neuronal cytoskeleton, axonal transport defects, and progressive neurodegeneration in Drosophila. Mol Biol Cell 16:2433-2442. CrossRef Medline

Billups D, Hanley JG, Orme M, Attwell D, Moss SJ (2000) GABAC receptor sensitivity is modulated by interaction with MAP1B. J Neurosci 20:86438650. Medline

Bouquet C, Soares S, von Boxberg Y, Ravaille-Veron M, Propst F, Nothias F (2004) Microtubule-associated protein 1B controls directionality of growth cone migration and axonal branching in regeneration of adult dorsal root ganglia neurons. J Neurosci 24:7204-7213. CrossRef Medline

Brenman JE, Topinka JR, Cooper EC, McGee AW, Rosen J, Milroy T, Ralston HJ, Bredt DS (1998) Localization of postsynaptic density-93 to dendritic microtubules and interaction with microtubule-associated protein $1 \mathrm{~A}$. J Neurosci 18:8805-8813. Medline 
Dietzl G, Chen D, Schnorrer F, Su KC, Barinova Y, Fellner M, Gasser B, Kinsey K, Oppel S, Scheiblauer S, Couto A, Marra V, Keleman K, Dickson BJ (2007) A genome-wide transgenic RNAi library for conditional gene inactivation in Drosophila. Nature 448:151-156. CrossRef Medline

Dodge FA Jr, Rahamimoff R (1967) Co-operative action a calcium ions in transmitter release at the neuromuscular junction. J Physiol 193:419-432 Medline

Eriksson M, Samuelsson H, Samuelsson EB, Liu L, McKeehan WL, Benedikz E, Sundström E (2007) The NMDAR subunit NR3A interacts with microtubule-associated protein $1 \mathrm{~S}$ in the brain. Biochem Biophys Res Commun 361:127-132. CrossRef Medline

Eriksson M, Samuelsson H, Björklund S, Tortosa E, Avila J, Samuelsson EB, Benedikz E, Sundström E (2010) MAP1B binds to the NMDA receptor subunit NR3A and affects NR3A protein concentrations. Neurosci Lett 475:33-37. CrossRef Medline

Feng Y, Ueda A, Wu CF (2004) A modified minimal hemolymph-like solution, HL3.1, for physiological recordings at the neuromuscular junctions of normal and mutant Drosophila larvae. J Neurogenet 18:377-402. CrossRef Medline

Fouquet W, Owald D, Wichmann C, Mertel S, Depner H, Dyba M, Hallermann S, Kittel RJ, Eimer S, Sigrist SJ (2009) Maturation of active zone assembly by Drosophila Bruchpilot. J Cell Biol 186:129-145. CrossRef Medline

Gögel S, Wakefield S, Tear G, Klämbt C, Gordon-Weeks PR (2006) The Drosophila microtubule associated protein futsch is phosphorylated by Shaggy/Zeste-white 3 at an homologous GSK3beta phosphorylation site in MAP1B. Mol Cell Neurosci 33:188-199. CrossRef Medline

González-Billault C, Demandt E, Wandosell F, Torres M, Bonaldo P, Stoykova A, Chowdhury K, Gruss P, Avila J, Sánchez MP (2000) Perinatal lethality of microtubule-associated protein 1B-deficient mice expressing alternative isoforms of the protein at low levels. Mol Cell Neurosci 16:408-421. CrossRef Medline

González-Billault C, Avila J, Cáceres A (2001) Evidence for the role of MAP1B in axon formation. Mol Biol Cell 12:2087-2098. CrossRef Medline

Gonzalez-Billault C, Owen R, Gordon-Weeks PR, Avila J (2002) Microtubule-associated protein 1B is involved in the initial stages of axonogenesis in peripheral nervous system cultured neurons. Brain Res 943:56-67. CrossRef Medline

Graf ER, Valakh V, Wright CM, Wu C, Liu Z, Zhang YQ, DiAntonio A (2012) RIM promotes calcium channel accumulation at active zones of the Drosophila neuromuscular junction. J Neurosci 32:16586-16596. CrossRef Medline

Graf M, Brobeil A, Sturm K, Steger K, Wimmer M (2011) 14-3-3 beta in the healthy and diseased male reproductive system. Hum Reprod 26:59-66. CrossRef Medline

Halpain S, Dehmelt L (2006) The MAP1 family of microtubule-associated proteins. Genome Biol 7:224. CrossRef Medline

Hanley JG, Koulen P, Bedford F, Gordon-Weeks PR, Moss SJ (1999) The protein MAP-1B links $\mathrm{GABA}(\mathrm{C})$ receptors to the cytoskeleton at retinal synapses. Nature 397:66-69. CrossRef Medline

Hummel T, Krukkert K, Roos J, Davis G, Klämbt C (2000) Drosophila futsch/22C10 is a MAP1B-like protein required for dendritic and axonal development. Neuron 26:357-370. CrossRef Medline

Hurd DD, Saxton WM (1996) Kinesin mutations cause motor neuron disease phenotypes by disrupting fast axonal transport in Drosophila. Genetics 144:1075-1085. Medline

Ikeda A, Zheng QY, Zuberi AR, Johnson KR, Naggert JK, Nishina PM (2002) Microtubule-associated protein $1 \mathrm{~A}$ is a modifier of tubby hearing (moth1). Nat Genet 30:401-405. CrossRef Medline

Kawasaki F, Zou B, Xu X, Ordway RW (2004) Active zone localization of presynaptic calcium channels encoded by the cacophony locus of Drosophila. J Neurosci 24:282-285. CrossRef Medline

Kittel RJ, Wichmann C, Rasse TM, Fouquet W, Schmidt M, Schmid A, Wagh DA, Pawlu C, Kellner RR, Willig KI, Hell SW, Buchner E, Heckmann M, Sigrist SJ (2006) Bruchpilot promotes active zone assembly, Ca2+ channel clustering, and vesicle release. Science 312:1051-1054. CrossRef Medline

Leenders AG, Lin L, Huang LD, Gerwin C, Lu PH, Sheng ZH (2008) The role of MAP1A light chain 2 in synaptic surface retention of Cav2.2 channels in hippocampal neurons. J Neurosci 28:11333-11346. CrossRef Medline
Marrus SB, Portman SL, Allen MJ, Moffat KG, DiAntonio A (2004) Differential localization of glutamate receptor subunits at the Drosophila neuromuscular junction. J Neurosci 24:1406-1415. CrossRef Medline

Matkovic T, Siebert M, Knoche E, Depner H, Mertel S, Owald D, Schmidt M, Thomas U, Sickmann A, Kamin D, Hell SW, Bürger J, Hollmann C, Mielke T, Wichmann C, Sigrist SJ (2013) The Bruchpilot cytomatrix determines the size of the readily releasable pool of synaptic vesicles. J Cell Biol 202:667-683. CrossRef Medline

Meixner A, Haverkamp S, Wässle H, Führer S, Thalhammer J, Kropf N, Bittner RE, Lassmann H, Wiche G, Propst F (2000) MAP1B is required for axon guidance and is involved in the development of the central and peripheral nervous system. J Cell Biol 151:1169-1178. CrossRef Medline

Montenegro-Venegas C, Tortosa E, Rosso S, Peretti D, Bollati F, Bisbal M, Jausoro I, Avila J, Cáceres A, Gonzalez-Billault C (2010) MAP1B regulates axonal development by modulating Rho-GTPase Rac1 activity. Mol Biol Cell 21:3518-3528. CrossRef Medline

Ni JQ, Liu LP, Binari R, Hardy R, Shim HS, Cavallaro A, Booker M, Pfeiffer BD, Markstein M, Wang H, Villalta C, Laverty TR, Perkins LA, Perrimon N (2009) A Drosophila resource of transgenic RNAi lines for neurogenetics. Genetics 182:1089-1100. CrossRef Medline

Nogales E (2001) Structural insight into microtubule function. Annu Rev Biophys Biomol Struct 30:397-420. CrossRef Medline

Noiges R, Eichinger R, Kutschera W, Fischer I, Nemeth Z, Wiche G, Propst F (2002) Microtubule-associated protein 1A (MAP1A) and MAP1B: light chains determine distinct functional properties. J Neurosci 22:21062114. Medline

O'Brien JE, Sharkey LM, Vallianatos CN, Han C, Blossom JC, Yu T, Waxman SG, Dib-Hajj SD, Meisler MH (2012) Interaction of voltage-gated sodium channel Nav1.6 (SCN8A) with microtubule-associated protein Map1b. J Biol Chem 287:18459-18466. CrossRef Medline

Oheim M, Kirchhoff F, Stühmer W (2006) Calcium microdomains in regulated exocytosis. Cell cCalcium 40:423-439. CrossRef Medline

Orbán-Németh Z, Simader H, Badurek S, Tranciková A, Propst F (2005) Microtubule-associated protein $1 \mathrm{~S}$, a short and ubiquitously expressed member of the microtubule-associated protein 1 family. J Biol Chem 280:2257-2265. CrossRef Medline

Pangratz-Fuehrer S, Bubna-Littitz H, Propst F, Reitsamer H (2005) Mice deficient in microtubule-associated protein MAP1B show a distinct behavioral phenotype and altered retina function. Behav Brain Res 164: 188-196. CrossRef Medline

Parks AL, Cook KR, Belvin M, Dompe NA, Fawcett R, Huppert K, Tan LR, Winter CG, Bogart KP, Deal JE, Deal-Herr ME, Grant D, Marcinko M, Miyazaki WY, Robertson S, Shaw KJ, Tabios M, Vysotskaia V, Zhao L, Andrade RS, et al. (2004) Systematic generation of high-resolution deletion coverage of the Drosophila melanogaster genome. Nat Genet 36: 288-292. CrossRef Medline

Pattnaik B, Jellali A, Sahel J, Dreyfus H, Picaud S (2000) GABAC receptors are localized with microtubule-associated protein 1B in mammalian cone photoreceptors. J Neurosci 20:6789-6796. Medline

Pielage J, Cheng L, Fetter RD, Carlton PM, Sedat JW, Davis GW (2008) A presynaptic giant ankyrin stabilizes the NMJ through regulation of presynaptic microtubules and transsynaptic cell adhesion. Neuron 58:195209. CrossRef Medline

Reese M, Sánchez-Pedregal VM, Kubicek K, Meiler J, Blommers MJ, Griesinger C, Carlomagno T (2007) Structural basis of the activity of the microtubule-stabilizing agent epothilone a studied by NMR spectroscopy in solution. Angewandte Chemie 46:1864-1868. CrossRef Medline

Rizzoli SO, Betz WJ (2005) Synaptic vesicle pools. Nat Rev Neurosci 6:5769. CrossRef Medline

Rohrbough J, Pinto S, Mihalek RM, Tully T, Broadie K (1999) latheo, a Drosophila gene involved in learning, regulates functional synaptic plasticity. Neuron 23:55-70. CrossRef Medline

Roos J, Hummel T, Ng N, Klämbt C, Davis GW (2000) Drosophila futsch regulates synaptic microtubule organization and is necessary for synaptic growth. Neuron 26:371-382. CrossRef Medline

Ruiz-Canada C, Ashley J, Moeckel-Cole S, Drier E, Yin J, Budnik V (2004) New synaptic bouton formation is disrupted by misregulation of microtubule stability in aPKC mutants. Neuron 42:567-580. CrossRef Medline

Sanyal S (2009) Genomic mapping and expression patterns of C380, OK6 
and D42 enhancer trap lines in the larval nervous system of Drosophila. Gene Expr Patterns 9:371-380. CrossRef Medline

Schneggenburger R, Sakaba T, Neher E (2002) Vesicle pools and short-term synaptic depression: lessons from a large synapse. Trends Neurosci 25: 206-212. CrossRef Medline

Söderberg $\mathrm{O}$, Gullberg $\mathrm{M}$, Jarvius $\mathrm{M}$, Ridderstråle $\mathrm{K}$, Leuchowius KJ, Jarvius J, Wester K, Hydbring P, Bahram F, Larsson LG, Landegren U (2006) Direct observation of individual endogenous protein complexes in situ by proximity ligation. Nat Methods 3:995-1000. CrossRef Medline

Takei Y, Teng J, Harada A, Hirokawa N (2000) Defects in axonal elongation and neuronal migration in mice with disrupted tau and maplb genes. J Cell Biol 150:989-1000. CrossRef Medline

Thanawala MS, Regehr WG (2013) Presynaptic calcium influx controls neurotransmitter release in part by regulating the effective size of the readily releasable pool. J Neurosci 33:4625-4633. CrossRef Medline

Tortosa E, Montenegro-Venegas C, Benoist M, Härtel S, González-Billault C, Esteban JA, Avila J (2011) Microtubule-associated protein 1B (MAP1B) is required for dendritic spine development and synaptic maturation. J Biol Chem 286:40638-40648. CrossRef Medline

Trotta N, Orso G, Rossetto MG, Daga A, Broadie K (2004) The hereditary spastic paraplegia gene, spastin, regulates microtubule stability to modulate synaptic structure and function. Curr Biol 14:1135-1147. CrossRef Medline

Vizlin-Hodzic D, Runnberg R, Ryme J, Simonsson S, Simonsson T (2011) SAF-A forms a complex with BRG1 and both components are required for RNA polymerase II mediated transcription. PloS one 6:e28049. CrossRef Medline

Wagh DA, Rasse TM, Asan E, Hofbauer A, Schwenkert I, Dürrbeck H, Buchner S, Dabauvalle MC, Schmidt M, Qin G, Wichmann C, Kittel R, Sigrist SJ, Buchner E (2006) Bruchpilot, a protein with homology to ELKS/CAST, is required for structural integrity and function of synaptic active zones in Drosophila. Neuron 49:833-844. CrossRef Medline

Xie R, Wang F, McKeehan WL, Liu L (2011) Autophagy enhanced by microtubule- and mitochondrion-associated MAP1S suppresses genome instability and hepatocarcinogenesis. Cancer Res 71:7537-7546. CrossRef Medline

Zervas M, Opitz T, Edelmann W, Wainer B, Kucherlapati R, Stanton PK (2005) Impaired hippocampal long-term potentiation in microtubuleassociated protein 1B-deficient mice. J Neurosci Res 82:83-92. CrossRef Medline

Zou B (2007) A role for MAP1 in synaptic function revealed through ineractions with presynaptic calcium channels in Drosophila. Abstract 3380810, The Pennsylvania State University.

Zou B, Yan H, Kawasaki F, Ordway RW (2008) MAP1 structural organization in Drosophila: in vivo analysis of FUTSCH reveals heavy- and lightchain subunits generated by proteolytic processing at a conserved cleavage site. Biochem J 414:63-71. CrossRef Medline

Zucker RS, Regehr WG (2002) Short-term synaptic plasticity. Annu Rev Physiol 64:355-405. CrossRef Medline 